This item was submitted to Loughborough's Research Repository by the author.

Items in Figshare are protected by copyright, with all rights reserved, unless otherwise indicated.

\title{
The yin and yang nature of coopetition activities: non-linear effects and the moderating role of competitive intensity for internationalised firms
}

\section{PLEASE CITE THE PUBLISHED VERSION}

https://doi.org/10.1108/IMR-01-2019-0018

\section{PUBLISHER}

Emerald Publishing Limited

VERSION

AM (Accepted Manuscript)

\section{PUBLISHER STATEMENT}

This paper was accepted for publication in the journal International Marketing Review and the definitive published version is available at https://doi.org/10.1108/IMR-01-2019-0018.

LICENCE

CC BY-NC 4.0

\section{REPOSITORY RECORD}

Crick, Jim, and Dave Crick. 2020. "The Yin and Yang Nature of Coopetition Activities: Non-linear Effects and the Moderating Role of Competitive Intensity for Internationalised Firms". Loughborough University. https://hdl.handle.net/2134/11295305.v1. 
THE YIN AND YANG NATURE OF COOPETITION ACTIVITIES: NON-LINEAR EFFECTS AND THE MODERATING ROLE OF COMPETITIVE INTENSITY FOR INTERNATIONALISED FIRMS

\begin{tabular}{|r|l|}
\hline Journal: & International Marketing Review \\
\hline Manuscript ID & IMR-01-2019-0018.R3 \\
\hline Manuscript Type: & Original Article \\
\hline Keywords: & $\begin{array}{l}\text { Coopetition activities, Market performance, Competitive intensity, } \\
\text { Resource-based theory, Relational view, Yin and yang concept }\end{array}$ \\
\hline
\end{tabular}

\section{SCHOLARONE ${ }^{\text {m }}$ \\ Manuscripts}




\title{
THE YIN AND YANG NATURE OF COOPETITION ACTIVITIES: NON-LINEAR EFFECTS AND THE MODERATING ROLE OF COMPETITIVE INTENSITY FOR INTERNATIONALISED FIRMS
}

\begin{abstract}
Purpose - This paper draws upon the Yin and Yang concept of Chinese philosophy within a Western context to examine coopetition, namely, the firm-level behaviours associated with the paradoxical forces of cooperativeness and competitiveness. Earlier studies suggest that coopetition has a positive relationship with company performance. Consideration of this relationship has typically been linear and without moderating factors. Consequently, underpinned by resource-based theory and the relational view, the purpose of this paper is to examine the non-linear (inverted U-shaped) relationship between coopetition and company performance under the moderating role of competitive intensity.

Design/methodology/approach - The study utilised survey data from a sample of 101 vineyards and wineries in New Zealand. After purifying the operationalisations through several multivariate techniques, testing of the research hypotheses and control paths were through hierarchical regression. The statistical results passed all major assessments of reliability and validity (together with common method variance). Furthermore, 20 semistructured interviews took place to offer unique insights to explain the underlying mechanisms behind the quantitative results.
\end{abstract}

Findings - The results indicated that coopetition has a non-linear (inverted U-shaped) relationship with market performance. Somewhat surprisingly, the non-linear relationship between coopetition activities and market performance did not become greater in magnitude as competitive intensity increases (a negative moderation effect). The mixed methods results highlighted that firms must strike an effective balance between the paradoxical forces of cooperativeness and competitiveness across their product-market strategies. If they can do so, they increase the chances of performing better in their domestic and international markets.

Practical implications - Owner-managers should collaborate with competitors that they trust to access new resources, capabilities, and opportunities that would not exist under individualistic business models. However, they should not engage in excessive degrees of coopetition, as there could be negative effects on their market performance. More importantly, owner-managers should be aware that potential inter-firm tensions need managing. For instance, trust and reciprocity need building with rivals offering complementary products and services, especially in highly competitive markets - where limited opportunities exist.

Originality/value - This paper contributes to the existing literature by developing and testing a conceptual framework examining the nature of the relationship between coopetition activities and market performance using non-linear (inverted U-shaped) and moderating effects. Indeed, this investigation addresses a debate between two schools-of-thought concerning the impact of competitive intensity on the coopetition paradox, namely, by offering unique insights based on a mixed methods research design. Additionally, this study helps to explain the coopetition construct through the Yin and Yang concept to highlight how the paradoxical forces of cooperativeness and competitiveness can create harmful outcomes for organisations if they do not manage them effectively (across domestic and international markets). Furthermore, support existed for resource-based theory and the relational view being appropriate lenses for studying the complexities of the relationship between coopetition activities and market performance. This article ends with some practitioner implications, alongside a series of limitations and avenues for future research.

Keywords - Coopetition activities, market performance, competitive intensity, resource-based theory, relational view, Yin and Yang concept.

Classification - Research paper. 


\section{Introduction}

"The supreme art of war is to subdue the enemy without fighting" (Sun Tzu, 1963, p. 63).

For many organisations, engaging in coopetition (or coopetition activities) is a fundamental marketing decision (Bengtsson and Kock, 2000; Rusko, 2011; Bengtsson and Raza-Ullah, 2016; Bouncken and Fredrich, 2016; Hoffmann et al., 2018; Ryan et al., 2019). It is the interplay between cooperation and competition, involving rival firms managing the paradoxical forces of cooperativeness and competitiveness (through the sharing of resources and capabilities) to achieve mutually beneficial outcomes (Raza-Ullah et al., 2014; Gnyawali et al., 2016; Gnyawali and Charleton, 2018; Chai et al., 2019). More formally, coopetition is defined as "a paradoxical relationship between two or more actors, regardless of whether they are involved in horizontal or vertical relationships, simultaneously involved in cooperative and competitive interactions" (Bengtsson and Kock, 2014, p. 180). As such, by engaging in coopetition, companies can obtain new resources, capabilities, and opportunities that would not exist under individualistic business models (Ritala et al., 2014; Velu, 2016). Consequently, it is not surprising that researchers have been interested in the performance-enhancing benefits of coopetition strategies (Rindfleisch and Moorman, 2003; Bouncken and Kraus, 2013; Czakon and Czernek, 2016; Bouncken et al., 2018; reference withheld).

A key theme surrounding this body of knowledge is that higher-levels of coopetition activities are likely to yield improvements in various forms of company performance (Ritala, 2012; Estrada et al., 2016; Hannah and Eisenhardt, 2018). Nevertheless, owner-managers need to manage the paradoxical forces of cooperativeness and competitiveness when engaging in coopetition strategies (Dahl, 2014; Mattsson and Tidstrom, 2015; Arslan, 2018). Indeed, some researchers have found that coopetition has a non-linear (inverted U-shaped) relationship with company performance, as it could be hard to differentiate between the point that cooperation ends and the stage when competitiveness resumes (Luo et al., 2007; Crick, 2019). The existing literature remains under-researched in respect of the implications for organisations if they engage in "too little" or "too much" coopetition and ways to explain the variance of this diminishing-returns effect. For example, it is unclear whether environmental contingencies (like competitive intensity) could affect this potential non-linear (inverted U-shaped) relationship (Ang, 2008; Park et al., 2014). Consequently, it is of interest to establish whether competitive intensity has a positive or negative impact on the non-linear (inverted U-shaped) relationship between coopetition activities and company performance. Such conceptualisations and empirical 
assertions address a debate pertaining to the benefits and drawbacks of coopetition strategies in domestic and international product-markets (following Crick, 2019).

This current study builds upon existing work that has examined the non-linear (inverted U-shaped) relationship between coopetition and company performance (Luo et al., 2007; Ang, 2008; Crick, 2019). Linking with the themes of this special issue, the Yin and Yang concept of Chinese philosophy helps to explain how firms should strike an effective balance when managing the interplay between cooperation and competition (see Chen, 2008; Raza-Ullah et al., 2014; Gnyawali et al., 2016; Stadtler and Van Wassenhove, 2016). The Yin and Yang concept is a Chinese (Taoist) philosophy that examines dualism, describing that seemingly contrasting forces (like male versus female energy) can be inter-dependent and complementary (Styles and Ambler, 2003; Fletcher and Fang, 2006; Gao et al., 2018). This paper extends these earlier conceptualisations with its research objective, namely, to utilise the Yin and Yang concept to explain the non-linear (inverted Ushaped) relationship between coopetition and company performance under the moderating role of competitive intensity. This research is timely and significant, as the use of the Yin and Yang concept extends and strengthens past findings that have emphasised that coopetition is comprised of the paradoxical forces of cooperativeness and competitiveness, but have overlooked how environmental contingencies could affect this balance (see Chen, 2008; Raza-Ullah et al., 2014; Mattsson and Tidstrom, 2015; Gnyawali et al., 2016).

To achieve the research objective, this investigation draws upon resource-based theory and the relational view (as per Barney, 1991; Hunt and Morgan, 1995; Dyer and Singh, 1998; Chetty and Wilson, 2003; Lavie, 2006; Dyer et al., 2018) to develop and test a conceptual framework pertaining to the nature of the relationship between coopetition and company performance. For clarity, the Yin and Yang concept is not the underpinning theory of this paper. Instead, it is a Chinese philosophy (used in a Western context) to explain the coopetition paradox (following Chen, 2008; Raza-Ullah et al., 2014). The Yin and Yang concept focuses on the need to balance the paradoxical forces of cooperativeness and competitiveness (Mattsson and Tidstrom, 2015; Gnyawali et al., 2016); this article extends these earlier conceptualisations by highlighting whether competitive intensity could help or hinder this balance (Crick, 2019). Hence, it is of interest to examine the Yin and Yang nature of coopetition to explore how this Eastern philosophy translates (or requires adaptation) towards organisations competing in Western contexts (building upon Fang, 2006). Following a review of the literature (Barney, 1991; Dyer and Singh, 1998; Lavie, 2006; Dyer et al., 2018), resource-based theory and the relational 
view were appropriate theoretical lenses to explore this Chinese philosophy and examine the nature of the relationship between coopetition activities and company performance. By conducting research across domestic and international product-market contexts, four contributions arise:

1. The study builds on resource-based theory and the relational view to enhance understanding of the nature of the relationship between coopetition activities and company performance (non-linear inverted U-shaped - and moderating effects) (extending Lavie, 2006; Luo et al., 2007; Ang, 2008; Dyer et al., 2018; Crick, 2019).

2. In line with the themes of this special issue, investigation takes place of the Yin and Yang concept as an Eastern philosophy applied to coopetition in a Western context to provide unique insights into the paradoxical forces of cooperativeness and competitiveness (building upon Fang, 2006; Chen, 2008; Raza-Ullah et al., 2014; Mattsson and Tidstrom, 2015).

3. New evidence highlights the role of trust and complementary relationships with evidence of coopetition strategies across domestic and international product-markets (following Park et al., 2014; Virtanen and Kock, 2016; Geldes et al., 2017).

4. The complexities of the competitive business environment are acknowledged when evaluating the coopetition activities - company performance relationship, in terms of addressing two schools-ofthought surrounding how competitive intensity impacts the coopetition paradox (linking with Chetty and Wilson, 2003; Luo, 2005; Luo and Tung, 2007; Felzensztein et al., 2019).

To make the above-mentioned contributions, first, a review takes place of the pertinent literature. Second, the conceptual framework, research hypotheses, and control paths follow. Third, consideration then takes place regarding the adopted methodology. Fourth, the empirical findings are outlined (quantitative and qualitative data). Fifth, discussion follows these findings in relation to the extant literature. Sixth, the study is concluded, with some practitioner implications and a series of limitations and avenues for future research.

\section{Framing literature}

\section{Coopetition activities}

A body of literature exists involving the notion of coopetition with early work by Brandenburger and Nalebuff (1996) investigating it as an organisation-wide mind-set associated with managers and functional-level 
employees believing that collaborating with competitors is a performance-driving strategy. Later, Bengtsson and Kock (1999) conceptualised the coopetition construct as being a set of firm-level behaviours pertaining to the sharing of resources and capabilities between industry rivals. Interestingly, the behavioural view of coopetition has been favoured across many studies (Luo et al., 2007; Rusko, 2011; Ritala et al., 2014; Shu et al., 2017; Granata et al., 2018). Resource-sharing activities involve firms lending/borrowing tangible assets, such as equipment, whereas, capability-sharing activities include firms pooling assets, like knowledge and experience (Crick, 2018). Bengtsson and Kock (2000) provided an early conceptualisation of the coopetition construct. They highlighted that coopetition can occur in informal and formal capacities between two competing entities. Later, these authors extended coopetition to apply to more than two competitors (see Bengtsson and Kock, 2014). The behavioural view of coopetition has emphasised that such activities are the interplay between cooperation and competition (Park et al., 2014; Bengtsson et al., 2016; Gnyawali and Charleton, 2018; Hoffmann et al., 2018; Chai et al., 2019). However, regardless of the extent to which businesses share resources and capabilities with their coopetition partners, the firms involved are nonetheless rivals (Dahl, 2014; Gnyawali et al., 2016; Arslan, 2018; Cui et al., 2018). This means that organisations should exercise caution when collaborating with their competitors, as it could be very difficult to differentiate between the paradoxical forces of cooperativeness and competitiveness (Luo et al., 2007; Ang, 2008; Park et al., 2014; Crick, 2019).

\section{Coopetition activities and company performance}

Various studies have explored the positive link between coopetition activities and company performance (Bouncken and Kraus, 2013; Felzensztein et al., 2014; Bouncken et al., 2018). Existing research suggests that if companies collaborate with their competitors, they can acquire new resources, capabilities, and opportunities that would not exist under individualistic business models (Bengtsson and Kock, 2000; Lavie, 2006; Ritala et al., 2014; Velu, 2016; Hannah and Eisenhardt, 2018). However, an under-researched issue surrounds whether there are limited performance consequences of coopetition and the potential for a diminishing-returns effect (Luo et al., 2007; Ang, 2008; Park et al., 2014; reference withheld). Furthermore, certain moderators that could affect the relationship between coopetition activities and company performance remain under-researched (Ritala, 2012; Bengtsson et al., 2016). This current study contributes to this under-researched area by 
examining the non-linear (inverted U-shaped) relationship between coopetition activities and market performance under the moderating role of competitive intensity. Put another way, this investigation seeks to evaluate whether there can be "too little" or "too much" coopetition and the potential for environmental issues, notably competitive intensity, to help or hinder such performance outcomes (building upon, Ang, 2008; Ritala, 2012; Crick, 2019). This contribution extends the view that the coopetition - company performance relationship is complex, as opposed to being linear and straightforward (following Shu et al., 2017; Hoffmann et al., 2018).

\section{International forms of coopetition activities}

Much of the research pertaining to coopetition activities examines domestic settings, involving two or more industry rivals collaborating within the same county (Rindfleisch and Moorman, 2003; Rusko, 2011; Dahl, 2014; Velu, 2016). Indeed, the research examining international forms of coopetition has typically focused on the strategies of multinational corporations, rather than smaller organisations (Luo, 2005; Luo and Tung, 2007; Ranganathan et al., 2018). In this current study, examination takes place regarding coopetition activities among smaller firms that compete for an array of domestic and international product-markets (building upon Chetty and Wilson, 2003; Felzensztein et al., 2019). Since the notion of competitive intensity affects firms domestically and internationally (Kohli and Jaworski, 1990; Jaworski and Kohli, 1993; Grewal and Tansuhaj, 2001; Cadogan et al., 2003), it is of interest to investigate how competitive intensity might affect firms with domestic and international product-market strategies. Consequently, examination takes place regarding the impact of competitive intensity to explain how this aspect of the business environment might affect the paradoxical forces of cooperativeness and competitiveness. Building upon earlier studies, the moderating role of competitive intensity sheds light on the contingent view of the coopetition construct (Shu et al., 2017; Hoffmann et al., 2018). That is, competitive intensity could de-stabilise the potentially non-linear (inverted Ushaped) relationship between coopetition activities and company performance (building upon Crick, 2019). Likewise, competitive intensity might provide organisations with increased scope to engage in effective (performance-driving) forms of coopetition, since they can be more selective of which rivals that they share resources and capabilities with (Felzensztein et al., 2012; Geldes et al., 2017; Granata et al., 2018). 


\section{Yin and Yang concept and coopetition activities}

As discussed later, the underpinning theories of this paper were resource-based theory and the relational view (Barney, 1991; Hunt and Morgan, 1995; Dyer and Singh, 1998; Lavie, 2006; Dyer et al., 2018). These theoretical perspectives were appropriate for studying the nature of the relationship between coopetition activities and company performance (non-linear - inverted U-shaped - and moderating effects). It is nevertheless important to first conceptualise the Yin and Yang concept, especially, its association with coopetition activities. According to Fletcher and Fang (2006), the Yin and Yang concept is a Chinese (Taoist) philosophy, highlighting that certain paradoxical forces (including beliefs, behaviours, and attitudes) can be inter-connected, complementary, and provide counter-balance to those managing these dynamics. Moreover, "Yin represents female energy (the moon, night, water, weakness, darkness, mystery, softness, and passivity), whereas, Yang stands for male energy (the sun, day, fire, strength, brightness, clearness, hardness, and activity)" (Fang, 2010, p. 159). This notion of paradoxical forces features across the broader marketing literature (Jancic and Zabkar, 2002; Henderson et al., 2003; Styles and Ambler, 2003; Mattsson and Tidstrom, 2015; Stadtler and Van Wassenhove, 2016; Gao et al., 2018). For example, Styles and Ambler (2003) examined how managers in highly-relational cultures, like China, need to integrate transactional and relational practices to yield successful outcomes (such as higher-levels of company performance). Styles and Ambler (2003) recommended that relational and transactional perspectives are not necessarily separate issues, but potentially paradoxical forces that are compatible and helpful to the long-term success of organisations in their markets.

As shown in Figure 1, within the Yin and Yang concept, "there is a dot of black in the white and a dot of white in the black... Opposites contain within them the seeds of the other and together form a dynamic unity (Chen, 2001). The Yin and Yang depend on each other, exist within each other, and succeed each other at different points in time" (Fang, 2006, p. 52). Fang (2006) argued that the Yin and Yang concept is deeply-embedded within Chinese philosophy and has direct connections with how the Chinese people follow different teachings, adapt their behaviours, and engage in business practices (like negotiation). Interestingly, Fang (2006) noted that the Yin and Yang concept links with how Chinese organisations manage cooperative and competitive behaviours to negotiate business deals with Western counter-parts. Linking with the themes of this special issue, extension takes place of Fang's (2006) conceptualisations in this current study to examine the 
paradoxical forces of cooperativeness and competitiveness within the capacity of coopetition activities. Building on Fang's (2006) helpful account of how the Yin and Yang concept (and other Chinese teachings) can be conveyed to Western practices; it is important to extend Fang's (2006) conceptualisations to apply the Eastern Yin and Yang concept to coopetition strategies implemented by organisations in Western contexts. Therefore, the Yin and Yang concept is related to the nature of the relationship between coopetition activities and company performance.

\section{[Insert Figure 1 about here]}

Although Fang's (2006) study mentioned the Yin and Yang concept in relation to the interplay between cooperation and competition, the existing literature has applied the Yin and Yang concept explicitly to the coopetition construct. Raza-Ullah et al. (2014) conceptualised that the cooperative and competitive forces that surround coopetition strategies are both complementary and paradoxical, but there can be unclear boundaries pertaining to these factors. Raza-Ullah et al. (2014) provided the example of one coopetition partner wanting to have long-term collaborative relations, whereas, others might behave opportunistically to yield short-term gains. Henceforth, for coopetition to be most effective, the firms involved need to acknowledge that regardless of the magnitude of cooperation, there will always be rivalry involved (Chen, 2008; Park et al., 2014; Bengtsson and Raza-Ullah, 2016; Gnyawali et al., 2016; Arslan, 2018; Cui et al., 2018). Returning to Bengtsson and Kock's (2000) seminal paper, these authors alluded to coopetition involving companies balancing these paradoxical forces. Such a task is likely to be difficult to achieve in practice, since it is hard to manage the interplay between cooperation and competition (Luo et al., 2007; Ang, 2008; Estrada et al., 2016; Hannah and Eisenhardt, 2018; Crick, 2019). In fact, Bengtsson and Kock (2000) indicated that some businesses are more cooperative than competitive (and vice-versa). Bengtsson and Kock (2000) found that although some firms can equally-distribute their collaborative and rivalrous activities, one of these forces is likely to prevail. Indeed, the extant literature suggests that rivalrous behaviours (as opposed to collaborative behaviours) are often stronger in coopetition strategies, since many owner-managers' aspirations to increase their sales, profits, market share, or other performance metrics can outweigh their collaborative activities (Bouncken and Kraus, 2013; Raza-Ullah et al., 2014; Tidstrom, 2014; Bouncken et al., 2018; reference withheld). 
As a related example, Stadtler and Van Wassenhove (2016) used the Yin and Yang concept to explore cooperative and competitive behaviours within a cross-sector partnership. They found that cooperative and competitive behaviours vary between managers and functional-level employees, as well as the corporate cultures of the firms involved. Stadtler and Van Wassenhove (2016) highlighted that if there is a "disconnect" between these paradoxical forces, there can be inter-firm tensions, including poor corporate profiling, knowledge-sharing (in a negative capacity), and role conflict. Likewise, they indicated that coopetitionoriented beliefs might not infuse into behavioural forms of coopetition if certain hierarchies and departments do not share such beliefs. To mitigate any dark-sides of coopetition activities, the businesses involved must set clear boundaries about how cooperation is "matched" against any competition, train members of staff, and communicate these strategies to internal and external stakeholders. Stadtler and Van Wassenhove (2016) suggested that if firms can undertake these tasks, they can balance the Yin and Yang concept underpinning the coopetition construct. Stadtler and Van Wassenhove's (2016) study was an inside-the-firm perspective of coopetition activities, but highlighted the potential drawbacks of such strategies.

Also linking with coopetition, Mattsson and Tidstrom (2015) argued that the Yin and Yang concept is a philosophical tool that explains the basic power of the universe - having business-level and society-wide implications. They focused on how coopetition is the interplay between cooperation and competition, but more crucially, is a paradoxical and complex notion that could be de-stabilised by the rivalrous behaviours of the entities involved. Mattsson and Tidstrom (2015, p. 3) summarised the Yin and Yang of coopetition through the following points, namely, "all change can be related to pairs of opposing forces. Opposing forces are mutually-dependent and contribute to each other. One force therefore contains the seeds of the other. The balance between opposing forces is in a state of constant change and should therefore be observed and analysed over time. The change process implies a continuous balancing to reach harmony. Interaction between opposing forces has society-wide effects." From a set of Finnish case studies, they found that the Yin and Yang of coopetition is sensitive, as competitive behaviours can distort this natural balance with cooperation (and viceversa). This means that while firms might use coopetition strategies to access new resources, capabilities, and opportunities (Ritala et al., 2014; Velu, 2016; Gnyawali and Charleton, 2018), the benefits of such activities could be distorted and harmed when these paradoxical forces are unhinged (Gnyawali et al., 2016; Hoffmann et al., 2018; reference withheld). 
Moreover, Mattsson and Tidstrom (2015) concluded their qualitative study with five research questions that can be used to direct future coopetition-based research. Specifically, Mattsson and Tidstrom (2015, pp. 13-14) asked - "under what circumstances do competitive processes and cooperative processes stimulate or stifle each other? Where are the seeds of cooperation to be found in competition (and vice-versa)? How does the pattern of domination of cooperation or competition change over time and how can this be described and explained? Can we understand the balancing process between cooperation and competition as coping efforts to reach harmony? How does interaction between competition and cooperation at the relational-level influence the interaction between competition and cooperation at the market-level (and vice-versa)?" This current study builds upon Mattsson and Tidstrom's (2015) conceptualisations by examining whether firms could be unsuccessful if they engage in "too little" or "too much" coopetition and could be affected by competitive intensity - as an environmental contingency (supplementing Crick, 2019). Put another way, it is of interest to explore whether competitive intensity balances or unhinges the Yin and Yang nature of coopetition activities. As explained later, using resource-based theory and the relational view (Barney, 1991; Hunt and Morgan, 1995; Dyer and Singh, 1998; Lavie, 2006; Dyer et al., 2018), this paper focuses on the Yin and Yang concept to examine the complexities of the link between coopetition and company performance.

Focusing on the cooperative and competitive facets of the coopetition construct, a famous Chinese proverb is that "the marketplace is a battlefield" (Fang, 2006, p. 53). In addition, Fang (2006, p. 53) stated that a key Chinese stratagem is to "kill with a borrowed knife. Make use of external resources for one's own gain." Arguably, this links with coopetition strategies, whereby, organisations can access new tangible and intangible assets from rival entities (following Bengtsson and Kock, 2000; Luo, 2005; Rusko, 2011; Ritala et al., 2014; Velu, 2016; Granata et al., 2018). However, when the time is right, coopetition partners could turn on one another and exhibit competitive behaviours (Cui et al., 2018). In other words, no matter how much collaboration occurs, coopetition is underpinned by competitive rivalry (Park et al., 2014; Bengtsston and Raza-Ullah, 2016; Arslan, 2018). Thus, the Yin and Yang concept is relevant to the coopetition construct and the paradoxical forces of cooperativeness and competitiveness (Chen, 2008; Raza-Ullah et al., 2014; Mattsson and Tidstrom, 2015; Gnyawali et al., 2016; Stadtler and Van Wassenhove, 2016). Yet, more research is needed to evaluate the underlying mechanisms behind the relationship between coopetition activities and company performance. For clarity, underpinned by resource-based theory and the relational view (Barney, 1991; Hunt 
and Morgan, 1995; Dyer and Singh, 1998; Lavie, 2006; Dyer et al., 2018), the Yin and Yang concept is proposed to be an appropriate and complementary tool that guides such future research. The study's conceptual framework, research hypotheses, and control paths follow in the next section.

\section{Theory and hypotheses \\ Resource-based theory and the relational view}

Resource-based theory involves how companies use resources and capabilities to yield higher-levels of performance (Hunt and Morgan, 1995; Zou and Stan, 1998; Hooley et al., 2005; Menguc and Auh, 2006; Barney, 2014). Resources are tangible assets, such as equipment and cash, whereas, capabilities are intangible assets, like knowledge and experience (Blesa and Ripolles, 2008; Ngo and O'Cass, 2012; Miocevic and Morgan, 2018). Under the resource-based view, a key managerial task is to evaluate whether organisational resources and capabilities fulfil the facets of the value, rarity, inimitability, and non-substitutability (VRIN) framework (Barney, 1991; Prahalad and Hamel, 1994; Morgan, 2012; Sun and Price, 2016). Such considerations examine whether a company's tangible and intangible assets can secure a sustainable competitive advantage (see Bowman and Ambrosini, 2003; Wiklund and Shepherd, 2003). In this paper, the VRIN framework is recognised as a foundational element of the resource-based view (Barney, 1991). However, these issues are extended, alongside more recent developments to resource-based theory; for instance, the role of the competitive business environment and relational factors (following Lavie, 2006; Barney, 2018).

Following on, an important addition to the resource-based view is the role of the competitive business environment. A debate between Barney (2001) and Priem and Butler (2001) helped to adapt resource-based theory to account for how volatile markets (like unpredictable competitive rivalry) can affect the performance consequences of organisational resources and capabilities. Investigations have conceptualised (and tested) how different aspects of the competitive business environment can moderate the link between firms' tangible and intangible assets (or certain strategies) and company performance (Cadogan et al., 2003; Kumar et al., 2011; Girod and Whittington, 2017). In this current study, the role of the competitive business environment is considered, as competitive intensity is proposed to moderate the non-linear (inverted U-shaped) relationship 
between coopetition activities and company performance (building upon Ang, 2008; Ritala, 2012; Geldes et al., 2017; Crick, 2019). In fact, earlier work indicates that the coopetition - company performance relationship could be contingent on market-level forces ${ }^{1}$ (Shu et al., 2017; Hoffmann et al., 2018). In other words, the complex relationship between coopetition activities and market performance could be affected by the degree of competitive intensity within a market (Bengtsson et al., 2016). That said however, a debate exists among scholars about the impact of the competitive business environment, namely, either positive or negative effects on the coopetition paradox (for a recent summary, see Crick, 2019). This current paper's conceptualisations and empirical assertions (driven by resource-based theory and the relational view, as well as the Yin and Yang concept) are utilised to address this debate.

However, the resource-enhancing nature of resource-based theory, by itself, is not enough to explain the relationship between coopetition and company performance. Linking with the role of the Yin and Yang concept, coopetition depends on the quality of the relationships between network partners (Chen, 2008; RazaUllah et al., 2014; Mattsson and Tidstrom, 2015; Gnyawali et al., 2016; Stadtler and Van Wassenhove, 2016). Thus, in this article, the relational view, together with the resource-based theory, provides the theoretical underpinning. The relational view examines the quality of firms' networks to yield superior performance within a market (Gronroos, 1997; Dyer and Singh, 1998). Resource-based theory and the relational view have been integrated and applied to coopetition strategies in earlier research (Lavie, 2006; Dyer et al., 2018; Crick, 2019), providing consistency with this current study. In fact, Barney (2018) suggested that a firm's relationships with stakeholders (potentially including competitors) affects performance outcomes. For clarity, by integrating resource-based theory and the relational view, this investigation examines several underresearched, but related issues pertaining to coopetition. Specifically, the potential for a non-linear (inverted Ushaped) link, the moderating role of competitive intensity, and the use of the Yin and Yang concept as an

\footnotetext{
${ }^{1}$ The authors acknowledge an anonymous reviewer for making this point. The coopetition - company performance relationship has been evaluated in numerous ways (conceptually and empirically), with linear (positive), non-linear (inverted U-shaped), and moderated links being explored (see Bengtsson and Kock, 2000; Luo et al., 2007; Ang, 2008; Ritala, 2012; Bouncken and Kraus, 2013; Bengtsson et al., 2016; Hannah and Eisenhardt, 2018; Crick, 2019). Thus, the conceptualisations made in this current study account for the complexities of the relationship between coopetition activities and company performance (Park et al., 2014; Bengtsson and Raza-Ullah, 2016; Shu et al., 2017; Hoffmann et al., 2018). Specifically, the subsequent conceptual framework evaluates the non-linear (inverted U-shaped) link between coopetition activities and market performance under the moderating role of competitive intensity.
} 
Eastern philosophy applied to a Western context (Barney, 1991; Dyer and Singh, 1998; Raza-Ullah et al., 2014; Mattsson and Tidstrom, 2015; Hannah and Eisenhardt, 2018; Crick, 2019).

Resource-based theory and the relational view also helped to explore the Yin and Yang of coopetition activities, as appropriate lenses. Furthermore, although the competitive business environment was a major extension to resource-based view (Barney, 2001; Priem and Butler, 2001), it has key connections to the relational view. In this paper, it is argued that if markets are highly-competitive, organisations have increased scope to be selective towards which rivals that they collaborate with (Felzensztein et al., 2012; Geldes et al., 2017; Granata et al., 2018). Hence, the relational view helped to uncover the vital nature of high-quality coopetition partnerships and some ways that competitive intensity might help or hinder the performance outcomes of coopetition activities (Dyer et al., 2018). This means that there is potential to employ the relational view and resource-based theory to evaluate whether competitive intensity moderates the non-linear (inverted U-shaped) link between coopetition activities and company performance ${ }^{2}$. Measurement of company performance can take place in various ways (Kanter, 1994; Ray et al., 2004; Morgan, 2012; O'Cass et al., 2015; Tan and Sousa, 2015; Katsikeas et al., 2016). In this current study, market performance was utilised to evaluate the success of coopetition strategies (see Ritala, 2012). Market performance is the degree to which organisations have improved their sales within their markets, relative to key competitors (Vorhies and Morgan, 2005; Morgan et al., 2009). Linking coopetition activities to the themes of the resource-based view and relational view, market performance was deemed to be an appropriate outcome variable (Crick, 2019).

\section{Conceptual framework}

The study's conceptual framework (Figure 2) contained two research hypotheses and nine control paths. First, it was anticipated that coopetition activities have a non-linear (inverted U-shaped) relationship with market performance. If firms engage in "too little" coopetition, they could risk struggling to compete within their markets, with an insufficient volume of resources and capabilities (Bengtsson and Kock, 2000; Rusko, 2011;

\footnotetext{
${ }^{2}$ The authors would like to thank an anonymous reviewer for recommending that competitive intensity is associated with resource-based theory and the relational view. In this current article, competitive intensity has conceptual links with both theoretical perspectives and is proposed as a moderator in the potentially non-linear (inverted U-shaped) relationship between coopetition activities and company performance (building upon Barney, 2001; Priem and Butler, 2001; Dyer $e t$ al., 2018). Yet, since the competitive business environment can affect the coopetition-company performance relationship in different respects (Ang, 2008; Ritala, 2012; Ritala and Hurmelinna-Laukkanen, 2013; Felzensztein et al., 2019), it is of interest to explore the underlying mechanisms behind this proposed effect.
} 
Bouncken and Fredrich, 2016; Granata et al., 2018). With “too much" coopetition, businesses might experience tensions with their rivals, diluted competitive advantages, and lost intellectual property, affecting the performance-enhancing outcomes of coopetition (Luo et al., 2007; Ang, 2008; Ritala and HurmelinnaLaukkanen, 2013; Tidstrom, 2014; Czakon and Czernek, 2016). Second, competitive intensity could positively moderate the non-linear (inverted U-shaped) relationship between coopetition activities and market performance. That is, competitive intensity could facilitate more effective opportunities for companies to work with industry rivals that are located within a close geographic proximity, target similar product-markets, and have synergetic business models (Felzensztein et al., 2012; Ritala et al., 2014; Virtanen and Kock, 2016; Geldes et al., 2017). Third, the nine control paths were firm size, firm age, industry experience, the facets of the entrepreneurial orientation construct (innovativeness, proactiveness, risk-taking, autonomy, and competitive aggressiveness), and degree of internationalisation (Hunt and Morgan, 1995; Hooley et al., 1998; Wiklund and Shepherd, 2003; Ramaswami et al., 2009; Kuivalainen et al., 2012; reference withheld; Mohr and Batsakis, 2014; Hagen et al., 2019). These constructs were conceptualised as factors that could also explain the variance of the outcome variable.

\section{[Insert Figure 2 about here]}

\section{Research hypotheses}

While certain studies have investigated the linear relationship between coopetition strategies and company performance (Rindfleisch and Moorman, 2003; Rusko, 2011; Ritala, 2012; Bouncken et al., 2018), a nonlinear (inverted U-shaped) relationship potentially exists (see Ang, 2008; Crick, 2019). Hence, it is of interest to examine the underlying mechanisms behind this potential diminishing-returns effect. For example, "cooperation with competitors needs to be carefully considered and judiciously executed because an overreliance on highly-intensive competitor alliances may be just as harmful as under-using such alliances. Excessive cooperation may lead to free-riding and opportunistic exploitation, a potential loss of proprietary, technological, and marketing capabilities, and a possible dulling of a firm's incentives to stay customerfocused" (Luo et al., 2007, p. 81). Thus, as challenging as it may be to achieve in practice, organisations must engage in an "optimal-level" of coopetition to mitigate any harm on their performance (Bengtsson and Kock, 2000; Bengtsson et al., 2016; Crick, 2019). Since coopetition surrounds the paradoxical forces of cooperativeness and competitiveness (Raza-Ullah et al., 2014; Mattsson and Tidstrom, 2015; Gnyawali et al., 
2016; Stadtler and Van Wassenhove, 2016), it is vital that businesses manage such forces correctly, so that they do not confuse these delicate boundaries (Park et al., 2014; Velu, 2016; Cui et al., 2018).

With "too little" coopetition, firms might struggle to compete within their markets, due to exploiting their resource-disadvantages (Rusko, 2011; Ritala et al., 2014; Granata et al., 2018). Under the resource-based view, small firms risk not being able to survive within their competitive business environments with a limited volume of resources and capabilities (Fahy and Smithee, 1999; Kozlenkova et al., 2014; Barney, 2018). Thus, by engaging in coopetition, smaller firms can obtain new resources, capabilities, and opportunities that overcome such resource-disadvantages and achieve their desired performance objectives (Crick, 2018). Put another way, "too little" coopetition could negatively impact market performance, since businesses might have scarce ways to create value for their customers if they were to utilise their own (limited) resources and capabilities (see Bengtsson and Kock, 2000; Felzensztein et al., 2012; Bengtsson and Raza-Ullah, 2016). Thus, "too little" coopetition could lead to certain resource-disadvantages and harm market performance (Rindfleisch and Moorman, 2003; Bouncken and Kraus, 2013; Granata et al., 2018). Furthermore, some smaller organisations might depend on their rivals' resources and capabilities, meaning that if they have not engaged in coopetition, they might be inefficient and ineffective in driving sales (Crick, 2019). This evidences why individualistic business models (where coopetition does not exist) have limited performance outcomes for the companies in question (Ritala et al., 2014; Velu, 2016).

With "too much" coopetition, firms might experience a range of problems, which are attributed to the potential diminishing-returns effect (Luo et al., 2007). For instance, if rival firms share "too many" resources and capabilities, they could lose vital information, including intellectual property and sources of competitive advantages (Ritala and Hurmelinna-Laukkanen, 2013; reference withheld). Likewise, businesses could experience tensions, such as working with competing entities that cannot separate the paradoxical forces of cooperativeness and competitiveness (Park et al., 2014; Tidstrom, 2014; Bengtsson et al., 2016). Hence, "too much" coopetition could mean that businesses lose control of the resources and capabilities that they share with industry rivals, potentially creating tensions by working with untrustworthy competitors (and those targeting similar product-markets) (Ang, 2008; Raza-Ullah et al., 2014; Czakon and Czernek, 2016; Bouncken et al., 2018; Cui et al., 2018). Under the relational view, the quality of inter-firm relationships is a core driver of company performance (Dyer and Singh, 1998; Lavie, 2006; Dyer et al., 2018). Hence, if cooperative and 
competitive forces are de-stabilised, market performance could decrease, since mutual trust could be damaged with rivalrous behaviours (Crick, 2019). As noted by Raza-Ullah et al. (2014), coopetition partnerships can be of a poor-quality, such as one rival wanting to have long-term relations, whereas, others might have narrow objectives and behave opportunistically for short-term gains. In these situations, there can be inter-firm conflict and power imbalances, due to an unhinged coopetition paradox (Park et al., 2014; Mattsson and Tidstrom, 2015; Gnyawali et al., 2016; Cui et al., 2018). These factors are likely to limit the performance-driving value of coopetition strategies.

Moreover, as mentioned earlier, firms could share excessive volumes of information with their rivals, leading to diluted competitive advantages and lost intellectual property (Luo et al., 2007; Ritala and HurmelinnaLaukkanen, 2013). Linking the non-linear (inverted U-shaped) relationship between coopetition activities and market performance with the Yin and Yang concept, the paradoxical forces of cooperativeness and competitiveness are at risk of being unbalanced (Mattsson and Tidstrom, 2015; Gnyawali et al., 2016; Arslan, 2018). Those researchers that have viewed coopetition as related to the Yin and Yang concept have emphasised the risks and rewards of balancing these opposite forces (Chen, 2008; Raza-Ullah et al., 2014; Stadtler and Van Wassenhove, 2016). Yet, if the Yin and Yang of coopetition strategies is unhinged, it is probable that there will be decreasing-levels of market performance (Mattsson and Tidstrom, 2015). Such an outcome could be driven by rising tensions (conflict and power imbalances) between industry rivals, unclear competitive boundaries, opportunistic behaviours, and firms becoming dependent on their competitors' resources and capabilities (Bengtsson and Kock, 2014; Tidstrom, 2014; Bengtsson et al., 2016; Hoffmann et al., 2018). In short, if firms engage in "too little" or "too much" coopetition, there can be negative effects on their market performance, meaning that they need to engage in an "optimal-level" of coopetition to mitigate such problems (Bengtsson and Kock, 2000; Tidstrom, 2009; Park et al., 2014; Hoffman et al., 2018). Therefore, it is expected that:

H1. A non-linear (inverted U-shaped) relationship exists between coopetition activities and market performance.

Competitive intensity is the degree of rivalry within a market (Kohli and Jaworski, 1990; Jaworski and Kohli, 1993; Grewal and Tansuhaj, 2001; Cadogan et al., 2003). While a non-linear (inverted U-shaped) relationship might exist between coopetition activities and market performance (Luo et al., 2007), it is of interest to examine 
how competitive intensity could affect this link ${ }^{3}$. As mentioned earlier, a debate exists between scholars about how competitive intensity moderates the non-linear (inverted U-shaped) relationship between coopetition activities and market performance (for a recent summary, see Crick, 2019). On the one hand, a negative moderation effect might occur, since increased competitiveness might deplete resources (Tidstrom, 2014), yield inter-firm tensions (Raza-Ullah et al., 2014; Czakon and Czernek, 2016; Cui et al., 2018), and dilute competitive advantages (Ritala and Hurmelinna-Laukkanen, 2013). In turn, competitive intensity could lessen the performance outcomes of coopetition, since firms might not be able to differentiate between the paradoxical forces of cooperativeness and competitiveness (Park et al., 2014; Mattsson and Tidstrom, 2014; Gnyawali et al., 2016). On the other hand, a positive moderation effect could occur. That is, while "too little" and "too much" coopetition is likely to be harmful for company performance (as per Luo et al., 2007; Ang, 2008; reference withheld), competitive intensity could lift (enhance) the performance outcomes of collaborating with competitors by accessing new opportunities in potentially complementary product-markets (Felzensztein et al., 2012; Virtanen and Kock, 2016).

As proposed below, this current study anticipates that the non-linear (inverted U-shaped) relationship between coopetition activities and market performance is positively moderated by competitive intensity. Put another way, the shape of the proposed association should be greater in magnitude as competitive intensity increases. With lower-levels of competitive intensity, organisations might have limited opportunities to access resources and capabilities from their competitors, affecting their resource-disadvantages (Granata et al., 2018; Crick, 2019). As markets become more competitive (and host a larger number of rivals), there could be more opportunities for effective (performance-driving) forms of coopetition activities to occur (Felzensztein et al., 2012; Geldes et al., 2017). Companies are likely to be more selective of which competitors that they are willing

\footnotetext{
${ }^{3}$ Competitive intensity, coopetition activities, and geographic proximity are different notions. Competitive intensity refers to the magnitude of competitive rivalry within a market (Kohli and Jaworski, 1990; Jaworski and Kohli, 1993). Coopetition activities are the firm-level behaviours associated with the interplay between cooperation and competition (see Bengtsson and Kock, 2000; Bouncken and Kraus, 2013; Estrada et al., 2016; Gnyawali and Charleton, 2018). Geographic proximity pertains to the physical distance between industry rivals (Felzensztein et al., 2014). In this current study, competitive intensity could relate to geographic proximity. If rivals are located within a close distance to one another, not only could there be more opportunities for effective coopetition strategies to be implemented, but also, firms can be more selective of which rivals that they work with (see Felzensztein et al., 2012; Geldes et al., 2017). Yet, coopetition might occur at a national-level, involving businesses collaborating with their competitors across multiple geographic regions (reference withheld). Henceforth, as competitive intensity increases, there could be more opportunities for effective forms of coopetition to be implemented within certain countries. The authors thank an anonymous reviewer for noting that the concepts are different, but potentially related.
} 
to cooperate with, in terms of being within a close geographic proximity (Felzensztein et al., 2014), targeting similar domestic and international product-markets (Chetty and Wilson, 2003; Virtanen and Kock, 2016), and having synergetic business models (reference withheld). Thus, competitive intensity could assist organisations to overcome some of the harmful consequences of coopetition. These negative outcomes include balancing the risk of engaging in "too little", vis-à-vis, "too much" coopetition, whereby, businesses chance competing with not enough resources and capabilities needed to survive within their markets - or the potential for inter-firm tensions, lost intellectual property, and diluted competitive advantages (Luo et al., 2007; Ang, 2008; Ritala and Hurmelinna-Laukkanen, 2013; Crick, 2019).

To illustrate this point, a large volume of research has been conducted on coopetition activities in the wine industry or agricultural markets (e.g., Felzensztein et al., 2012; Geldes et al., 2017; Granata et al., 2018). Such research had indicated that if wine regions (or multiple regions across a country) become more competitive, vineyards and wineries have increased scope to engage in performance-driving forms of coopetition (see Felzensztein et al., 2019). For instance, vineyards and wineries could have ample choice to decide which competitors that they share resources and capabilities with for mutually-beneficial outcomes, such as improved financial performance, regional growth, or even basic issues, like new knowledge and market intelligence (Crick, 2018). As explained later, the wine industry features as the empirical context for this current investigation. However, an emerging research area surrounds the factors that could moderate the relationship between coopetition activities and company performance (Ritala, 2012; Park et al., 2014; Bengtsson et al., 2016). Indeed, some authors have indicated that the coopetition - company performance relationship is complex, namely, various moderating factors could affect such an association (see Shu et al., 2017; Hoffmann et al., 2018). To connect with the themes of resource-based theory and the relational view, competitive intensity is proposed to moderate the link between coopetition activities and market performance (Crick, 2019). As mentioned earlier, in relation to the competitive business environment (as a contingency), there is a debate within this body of knowledge. Some researchers have argued that in highly-competitive markets, industry rivalry can limit the performance consequences of coopetition activities, as it encourages opportunistic behaviours between coopetition partners (Park et al., 2014; Raza-Ullah et al., 2014).

In contrast, Crick (2019) highlighted that due to the themes of the relational view, competitive intensity can facilitate effective forms of coopetition if there are high-quality inter-firm relationships. Nevertheless, it is of 
interest to evaluate whether competitive intensity is a positive contingency (moderator) in the coopetition activities - market performance relationship. Under the relational view, the quality of the networks that companies manage is vital to their performance (Dyer and Singh, 1998; Lavie, 2006; Dyer et al., 2018). That is, if rival entities do not trust one another (or are managing high-degrees of inter-firm tensions), such poorquality networks can limit the amount of resource and capability-sharing activities (Crick, 2019). Likewise, if trust exists between industry rivals, coopetition partners should receive the benefits of such strategies, with a free flow of tangible and intangible assets (Czakon and Czernek, 2016; Bouncken et al., 2018). Following the earlier wine industry and agricultural market illustrations, competitive intensity could facilitate effective forms of coopetition, since the increased collaborative opportunities provide a better choice of trustworthy coopetition partners that help firms to increase their market performance and other mutually-beneficial outcomes (Geldes et al., 2017; Granata et al., 2018; Felzensztein et al., 2019). Nonetheless, although the proposed non-linear (inverted U-shaped) relationship between coopetition activities and market performance might be greater in magnitude in higher-levels of competitive intensity (following Crick, 2019), there is still the prevailing issue of firms engaging in "too little" or "too much" coopetition (following Luo et al., 2007; Ang, 2008; Park et al., 2014; reference withheld).

Returning to the Yin and Yang concept, businesses are more likely to yield higher-levels of performance from their coopetition strategies if they can strike an effective balance between the paradoxical forces of cooperativeness and competitiveness (Raza-Ullah et al., 2014; Mattsson and Tidstrom, 2015; Gnyawali et al., 2016; Stadtler and Van Wassenhove, 2016). Therefore, if markets are highly-competitive, the increased opportunities for coopetition to occur could bring balance back to the Yin and Yang concept and stabilise these opposing forces. Put another way, competitive intensity could provide firms with performance-driving forms of industry rivalry to complement coopetition activities (Geldes et al., 2017; Crick, 2019). Since competitive intensity is a complex construct, affecting businesses domestically and internationally (Kohli and Jaworski, 1990; Jaworski and Kohli, 1993; Grewal and Tansuhaj, 2001; Cadogan et al., 2003), it could be that highlycompetitive markets facilitate ideal forms of coopetition activities. New entrants and existing rivals might provide organisations with certain resources, capabilities, and opportunities that would be harder to acquire not just under an individualistic business model (instances of "too little" coopetition), but also, in less competitive sectors (Bengtsson and Kock, 1999; Chetty and Wilson, 2003; Bengtsson and Raza-Ullah, 2016; 
Felzensztein et al., 2019). Indeed, this is likely to occur if the increased collaborative opportunities involve rival firms that can work together (and trust one another) to achieve mutually-beneficial outcomes, such as improved market performance (Virtanen and Kock, 2016). With higher-levels of competitive intensity, businesses have more scope to avoid some of the negative outcomes of coopetition activities, such as interfirm tensions, lost intellectual property, and diluted competitive advantages (Luo et al., 2007; Ang, 2008; Ritala and Hurmelinna-Laukkanen, 2013; Raza-Ullah et al., 2014; Bengtsson et al., 2016; Czakon and Czernek, 2016). As previously alluded to, while there are two schools-of-thought surrounding the impact of the competitive business environment (including competitive intensity) on the non-linear (inverted U-shaped) relationship between coopetition activities and market performance (see Crick, 2019), it is anticipated that a positive moderation effect should occur. Consequently, it follows that:

H2. The non-linear (inverted U-shaped) relationship between coopetition activities and market performance becomes greater in magnitude as competitive intensity increases.

\section{Control paths}

In addition to the research hypotheses, the outcome variable (namely, market performance) was controlled by firm size, firm age, industry experience, degree of internationalisation, and the dimensions of the entrepreneurial orientation construct (innovativeness, proactiveness, risk-taking, autonomy, and competitive aggressiveness). First, in terms of firm size, the resource-based view indicates that as firms become larger, they increase their chances of obtaining resource-advantages through possessing greater resources and capabilities to out-perform their industry rivals (Hunt and Morgan, 1995; Hooley et al., 1998; Ekeledo and Sivakumar, 2004; Morgan, 2012; Barney, 2014). Second, regarding firm age, the resource-based view has accounted for other ways that organisations can increase their performance, including through their heritage (Bahadir et al., 2009; Vorhies et al., 2011; Barney, 2018). An argument has been that older firms can outperform younger competitors with more knowledge on how to create value for their customers (as per Ramaswami et al., 2009; Mohr and Batsakis, 2014). Third, if businesses possess more industry experience (an organisational capability), they are likely to be competent in understanding how to operate successfully within their markets via knowing what strategies should improve their performance (Noble and Gruca, 1999; Purani and Sahadev, 2008). Fourth, companies that operate outside of their domestic markets potentially possess more opportunities to target a larger array of customers and can yield higher-levels of performance (Reid, 1983; 
Freeman et al., 2006; Cadogan et al., 2009; Kuivalainen et al., 2012; Hagen et al., 2019). This assumes that appropriate assessments of risk/rewards are undertaken (Spence and Crick, 2006; reference withheld). In fact, firms with higher-degrees of internationalisation are potentially likely to be open to more opportunities to improve their market performance (Axinn, 1988; Katsikeas et al., 2000; Kropp et al., 2006; reference withheld; Dubiel et al., 2018).

Fifth, entrepreneurial orientation is "the strategy-making processes that provide organisations with a basis for entrepreneurial decisions and actions" (Rauch et al., 2009, p. 762). Entrepreneurial orientation was used to control market performance, as it is a set of firm-level behaviours used to help firms to stay competitive within their markets, differentiate themselves from key competitors, and make more informed decisions pertaining to their industries (Lumpkin and Dess, 1996; Matsuno et al., 2002; Chen et al., 2012; Jin and Cho, 2018). Entrepreneurial orientation is a five-dimension variable, comprised of innovative, proactive, risk-taking, autonomous, and competitively aggressive behaviours (Sundqvist et al., 2012; Boso et al., 2013). If firms develop and launch innovative goods and services, they might attract new customers (Hurley and Hult, 1998). If decision-makers can act proactively to changes in their competitive business environment, they could improve their chances of positively addressing certain opportunities (Lumpkin and Dess, 1996). When engaging in risk-taking behaviours, if management teams are prepared to take chances in their business strategies, this might facilitate positive financial performance outcomes (Wiklund and Shepherd, 2003). If firms can complete projects and be self-directed, in terms of autonomous behaviours, they could run their operations efficiently and effectively, which in turn, might improve their success in their markets (Merlo and Auh, 2009). Management teams can employ competitively aggressive behaviours to differentiate their business models from their rivals and create value for customers (Combe and Greenley, 2004). By controlling market performance for the facets of the entrepreneurial orientation construct, this paper builds upon work that has linked coopetition to theory positioned at the marketing/entrepreneurship interface (Virtanen and Kock, 2016; reference withheld; Crick, 2018). The adopted methodology follows in the next section. 


\section{Methodology}

\section{Empirical context}

The empirical context for this investigation was the New Zealand wine industry, as prior research has found that it is a highly-cooperative and highly-competitive sector (Felzensztein et al., 2014; Crick, 2018). Since coopetition is the interplay between cooperation and competition (Bengtsson and Kock, 1999; Rusko, 2011; Bouncken and Kraus, 2013; Czakon and Czernek, 2016; Hoffmann et al., 2018), it was important to collect empirical data from an industry that exhibits high-degrees of cooperativeness and competitiveness (reference withheld). This also meant that the paradoxical forces underpinning the Yin and Yang concept of coopetition could be evaluated (building upon Chen, 2008; Raza-Ullah et al., 2014; Mattsson and Tidstrom, 2015; Gnyawali et al., 2016; Stadtler and Van Wassenhove, 2016). New Zealand is responsible for approximately $1.16 \%$ of worldwide wine production and is a growing market, in terms of supply and demand (The International Organisation of Vine and Wine, 2017). Additionally, the New Zealand wine industry hosts companies with varied degrees of internationalisation (Chetty and Wilson, 2003; reference withheld; Felzensztein et al., 2019). To examine how coopetition might vary across domestic and international productmarkets, it was necessary to select a setting with many internationalising businesses.

\section{Sampling frame}

The study's sampling frame was a public database containing firms within the broader "alcohol market" in New Zealand, including all vineyards and wineries. In its original form, this database contained numerous firms that were not part of the population of interest. From an original list of 1,348 companies, the research team deleted the following organisations from the database. First, 323 firms were not wine producers (like gin distilleries or craft breweries). Second, 212 organisations did not have working contact details (such as email addresses). Third, 49 companies were retailers (like supermarkets or liquor suppliers). Fourth, 38 entities were no longer trading. Once deletion took place of these various businesses from the sampling frame, 726 vineyards and wineries remained. Next, the research team randomly selected 80 companies for a pilot study (as discussed later). Thus, the final population for the core study was 646 vineyards and wineries. The research team compared this list against the New Zealand Winegrowers Association's (2018) website. This revealed that the 
726 businesses (including the pilot firms) were trading wine producers that were accessible for data collection purposes.

\section{Research methods}

The main research method in this study was an electronic survey (administered in 2018 via Qualtrics) that was utilised to test the research hypotheses and control paths. Division of this survey involved three core sections. First, some demographic questions were included to ask respondents about the characteristics of the sampled businesses. Second, the core variables involved the constructs used to test the research hypotheses and control paths. Third, the survey included a few instrumental variables to assess the data for common method variance and to check for evidence of face validity (as covered later). Further, 20 semi-structured interviews took place to supplement the survey data with some in-depth information about "how and why" the results existed. While statistical methods helped to explain the relationships between the constructs within the conceptual framework, they could not fully-explain the underlying mechanisms behind the issues that were best yielded by qualitative methods (Welch et al., 2011; Andriopoulos and Slater, 2013; Sharma et al., 2018). Thus, while the electronic survey was effective to test the research hypotheses and control paths, the semi-structured interviews could explain the meaning of the statistical results. Appendix 1 outlines the interview guide used in the qualitative stage (following Nemkova et al., 2012; Felzensztein et al., 2019).

\section{Data collection techniques}

The following data collection techniques were utilised in this investigation. First, after a draft of the electronic survey had been developed, it was pre-tested with a sample of academics $(n=10)$. Consultation focused on their theoretical knowledge, concerning whether the constructs were appropriately operationalised, as well as any issues pertaining to the underpinning theories of this investigation (reference withheld). Afterwards, the survey was pre-tested with a sample of practitioners $(n=15)$, namely, the owner-managers of New Zealand wine-producing firms, in terms of its readability and content (Reynolds and Diamantopoulos, 1998). Second, after the pre-testing stage, a pilot study was conducted, in which 20 usable responses were collected from a sub-sample of 80 companies. Third, the core study was implemented $(\mathrm{n}=81)$. The pilot study data indicated that the constructs captured a high-degree of variance, with acceptable scale reliabilities (Hunt et al., 1982). 
As no changes were made to the electronic survey after the pilot study, the research team merged the data from the core study with that from the pilot study $(\mathrm{n}=101)$ (as per Morgan and Hunt, 1994). As 101 observations (as a proportion of 726 companies) accounted for a $13.91 \%$ response rate, the researchers deemed that the study involved a satisfactory sample size, considering the availability of the key informants who were busy running their respective businesses.

Indeed, other studies in the marketing literature have collected smaller sample sizes. For example, Moorman (1995) collected 92 observations and tested a relatively complicated model - with such data passing all major robustness checks. As such, the sample size used within this current study was satisfactory to test the research hypotheses and control paths. Additionally, the research team conducted $t$-tests to check for evidence of early and late response bias, revealing non-significant differences (Armstrong and Overton, 1977). Fourth, contact took place with a sample of managers in 20 businesses to facilitate interview participation (in a semi-structured format), all of whom granted access. Selection of interviewees took place from firms with varying degrees of internationalisation (export ratios) to provide a variety of experiences in their international activities. Furthermore, data collection occurred across multiple wine regions for perspectives from companies across New Zealand (Charters et al., 2009; reference withheld). To emphasise an important point, the qualitative data were not used to produce generalisable findings, but rather, allowed the research team to obtain unique insights to supplement the core statistical results ${ }^{4}$ (see Welch et al., 2011; Andriopoulos and Slater, 2013; Sharma et al., 2018).

\section{Operationalisations of the constructs}

Before the scale purification stage, the constructs were operationalised as follows (Appendix 2 illustrates a full-list of the multi-item measurement scales). First, the coopetition activities construct was captured on a

\footnotetext{
${ }^{4}$ The most important element of the qualitative data was to explore the complexities of how competitive intensity could moderate the non-linear (inverted U-shaped) link between coopetition activities and market performance. That is, the interviews allowed the research team to delve deeper into how competitive intensity varies domestically and internationally (Kohli and Jaworski, 1990; Jaworski and Kohli, 1993; Grewal and Tansuhaj, 2001; Cadogan et al., 2003) - affecting the performance outcomes of coopetition activities in different ways. Indeed, the qualitative stage was utilised to address a debate among scholars about the impact of competitive intensity and if this is positive or negative in relation to the coopetition paradox (following Crick, 2019). The research team would like to thank an anonymous reviewer for recommending that more detail should be invested on the purpose of the follow-up interviews.
} 
seven-point Likert scale, with four items, ranging from: $1=$ very strongly disagree to $7=$ very strongly agree (adapted from Boucken and Kraus, 2013; Bouncken et al., 2018). Operationalisation of coopetition in earlier research has taken place in different ways. Some scholars have employed archival measures (Ang, 2008), other academics have used single-item proxies (Ritala, 2012), and more recently, coopetition has been operationalised as a multi-dimensional construct (reference withheld). Indeed, other measures have been developed and tested to capture the variance of the coopetition construct (Bengtsson et al., 2016; Shu et al., 2017; Czakon et al., 2019), but no single-agreed operationalisation exists. According to Bengtsson and RazaUllah (2016), researchers should include cooperative and competitive forces when operationalising coopetition. In other words, when measuring coopetition, it is necessary to utilise terminology associated with cooperative and competitive behaviours. This way, the interplay between cooperation and competition can be infused within the operationalisation of the coopetition construct. Other than its sourced material, the adopted measurement scale has been validated across various papers (Bouncken and Fredrich, 2016; Chai et al., 2019; reference withheld). This multi-item scale assesses the propensity of coopetition (or the degree of cooperation with competitors) and includes issues pertaining to cooperativeness and competitiveness.

Second, competitive intensity was measured using a seven-point Likert scale, with five items, ranging from: 1 $=$ very strongly disagree to 7 = very strongly agree (adapted from Jaworski and Kohli, 1993; Grewal and Tansuhaj, 2001). Third, market performance was measured using a seven-point Likert scale, with four items, ranging from: $1=$ much worse than competitors to $7=$ much better than competitors) (adapted from Vorhies and Morgan, 2005; Morgan et al., 2009). Fourth, regarding the control variables, operationalisation of firm size involved the number of full-time and part-time employees (see Peng and Luo, 2000). Measurement of firm age involved asking the respondents for the year of establishment for their companies, then subtracted from 2018 (the year of this study) (Vorhies et al., 2011). Capturing industry experience was via a new singleitem ratio scale that asked the respondents about the number of years they have in the global wine industry, ranging from: 0 to 60 years. Measurement of firms' degree of internationalisation was by asking the respondents to indicate the percentage of their annual sales that originates from their overseas markets, namely, their export ratios (as per Cadogan et al., 2009). Measurement of entrepreneurial orientation was via a fivecomponent construct, comprised of innovativeness (four items), proactiveness (three items), risk-taking (three items), autonomy (three items), and competitive aggressiveness (three items). These dimensions of 
entrepreneurial orientation were measured using seven-point Likert scales, ranging from: $1=$ very strongly disagree to 7 = very strongly agree (adapted from Sundqvist et al., 2012; Boso et al., 2013). Fifth, the survey ended with an informant quality scale to measure the extent to which the respondents were qualified to participate in the study. This measure involved a seven-point Likert scale, with three items, ranging from: $1=$ very strongly disagree to 7 = very strongly agree (adapted from Katsikeas et al., 2006; Hultman et al., 2009). Transformation took place of the single-item scales (firm size, firm age, industry experience, and degree of internationalisation) through natural logarithms to reduce their variances.

\section{Data analysis techniques}

The data analysis techniques were undertaken as follows. First, the research team examined the characteristics of the final sample and some descriptive statistics of the measures, namely, their means, medians, standard deviations (SDs), and variances (Churchill Jr., 1979). A wide variety of companies participated in this study, in terms of the descriptive statistics for the number of part-time and full-time employees, firm age, experience of the respondents, degree of internationalisation, number of export markets, and annual sales (Table 1).

\section{[Insert Table 1 about here]}

Second, checks took place of the initial scale reliabilities of the measurement scales using Cronbach's alpha coefficient $(\alpha)$. The research team explored whether improvement in the scale reliabilities would occur if deletion occurred for individual items, indicating no concerns (Peterson, 1994). The initial scale reliabilities for the coopetition activities $(\alpha=0.88)$, competitive intensity $(\alpha=0.89)$, market performance $(\alpha=0.91)$, innovativeness $(\alpha=0.87)$, proactiveness $(\alpha=0.80)$, risk-taking $(\alpha=0.88)$, competitive aggressiveness $(\alpha=$ $0.94)$, autonomy $(\alpha=0.90)$, and informant quality $(\alpha=0.93)$ constructs were acceptable (in excess of 0.70 ). Moreover, the inter-item correlations for each latent variable were high and significant (Churchill Jr., 1979). Third, an exploratory factor analysis took place using SPSS 23 to understand the factor structure of the multiitem scales via a principal component analysis extraction and a varimax rotation (Peterson, 2000). The KaiserMeyer-Olkin (KMO) test of sampling adequacy was utilised (0.66), alongside Bartlett's test of sphericity $\left(\chi^{2}\right.$ $=2,451.06 ; d f=496$; Sig. $=0.00)$, as well as recording the total variance explained $(80.75 \%)$ (Bloch et al., 2003). These statistical tests produced satisfactory results from the nine-factor solution (Table 2). 
Fourth, through LISREL 9.30, a confirmatory factor analysis was used (the measurement model), in which all variables that were used to test the hypothesised and control paths were included to purify the final operationalisations (Gerbing and Anderson, 1988; Cadogan et al., 2008). In addition to checking the modification indices, the research team deleted items with low factor loadings, high error variances, and nonsignificant $t$-values (Moorman, 1995), for which all multi-item constructs retained multiple items ${ }^{5}$ (Table 3).

[Insert Table 3 about here]

Fifth, a series of model fit indices were used to evaluate the confirmatory factor analysis (Cadogan et al., 2001). All model fit indices used during the confirmatory factor analysis were within the minimum benchmarks $\left(\chi^{2}=487.83 ; d f=331 ;\right.$ Sig. $=0.00 ; \chi^{2} / d f=1.47 ;$ RMSEA $=0.06 ; \mathrm{NNFI}=0.90 ; \mathrm{CFI}=0.92 ; \mathrm{IFI}=0.93 ; \mathrm{SRMR}$ $=0.05)$, suggesting that the data were well-suited to the measurement model. Sixth, calculation took place of the final scale reliabilities, with a focus on the Cronbach's alpha coefficients ( $\alpha$ ), composite reliabilities (CRs), and average variance extracted values (AVEs) (Peterson, 1994; Katsikeas et al., 2006). All the final scale reliabilities exceeded the minimum thresholds (Table 4).

\section{[Insert Table 4 about here]}

Seventh, to test the hypothesised and control paths, the research team utilised a six-step hierarchical regression analysis (Olson et al., 2005; Pham et al., 2017). In each regression model, the outcome variable was market performance. Step 1 involved testing the control paths, namely, firm size, firm age, industry experience, innovativeness, proactiveness, risk-taking, autonomy, competitive aggressiveness, and degree of internationalisation. Step 2 concerned adding the linear link between coopetition activities and market performance (the main effect). Step 3 involved the addition of the orthogonalised non-linear (inverted Ushaped) path to the model (as described later). Step 4 involved adding the main effect from the moderating

\footnotetext{
${ }^{5}$ During the confirmatory factor analysis, the error variances of the single-item scales (e.g., firm size) were manuallycalculated and inputted into the LISREL 9.30 software. Following the procedure undertaken by Cadogan et al. (2002), the research team subtracted the assumed scale reliability $(0.60)$ from 1.00 and multiplied this value $(0.40)$ by the variance of the item. Also, the following construct abbreviations were used for statistical purposes - coopetition activities (COOP), market performance (MARK), competitive intensity (COMP), firm size (SIZE), firm age (AGE), innovativeness (INNV), proactiveness (PRCT), risk-taking (RISK), autonomy (AUTO), competitive aggressiveness (CAGG), industry experience (INDS), degree of internationalisation (INTL), and informant quality (INQ).
} 
role of competitive intensity to the regression model (also described later). Step 5 concerned testing the orthogonalised interaction between the main effect (coopetition activities) and the moderator (competitive intensity). Step 6 involved evaluating the orthogonalised interaction between the non-linear (inverted Ushaped) effect - coopetition activities squared - and the moderator (competitive intensity). In each stage, the research team recorded the $\mathrm{R}^{2}$ and the adjusted $\mathrm{R}^{2}$ to examine the amount of variance of the outcome variable that was explained by the independent variables (Morgan et al., 2009). The change in the $\mathrm{R}^{2}$ values $\left(\Delta \mathrm{R}^{2}\right)$ were examined between the steps in the hierarchical regression analysis. By the final (nested) stage, the $\Delta \mathrm{R}^{2}$ (relative to the $\Delta F$-statistic) was significant.

When evaluating somewhat complex statistical models through multivariate techniques (like hierarchical regression or structural equation modelling), researchers must specify how they are testing their research hypotheses and control paths (Fornell and Larcker, 1981; Aiken and West, 1991; Contractor et al., 2006). In this current study, since the model-testing involved a non-linear (inverted U-shaped) link (H1) and a moderation effect on such a relationship (H2), the research team decided to use the final stage of the hierarchical regression analysis to yield the most accurate results. Specifically, the multivariate nature of the model-testing could occur when all the latent variables nested within the hierarchical regression analysis (Olson et al., 2005; Morgan et al., 2009). Cadogan et al. (2012) followed a similar approach, in which they employed covariance-based structural equation modelling, but nonetheless, tested their model once all constructs were nested within the statistical analysis. In this investigation, the two research hypotheses and nine control paths were tested in the final (nested) stage of the hierarchical regression analysis, as opposed to during earlier stages of the model (see Cadogan et al., 2005; French and Cadogan, 2011; reference withheld). Moreover, hierarchical regression was employed, as the conceptual framework (specifically, the hypothesised and control paths) was relatively straight forward, with one outcome variable and several independent variables - through the transformed constructs and control variables (Olson et al., 2005; Morgan et al., 2009).

To test the research hypotheses, the respective non-linear (inverted U-shaped) and moderating relationships were transformed through residual-centering to alleviate multi-collinearity (following Echambadi and Hess, 2007; Story et al., 2015). Once the final operationalisations had been established, residual-centering was 
employed via SPSS 23 to transform the constructs as follows ${ }^{6}$. The coopetition activities construct was squared and saved as a new variable. Subsequently, the squared term was regressed - with the coopetition activities construct serving as the independent variable. During this process, the unstandardised residuals were saved (orthogonalisation) and were used to test H1. A similar process followed to transform the moderator, whereby, the squared coopetition activities construct was multiplied by the competitive intensity variable. Afterwards, this new value was regressed - with the squared coopetition activities construct being used as the independent variable. In this regression analysis, the unstandardised residuals were saved and were used to test $\mathrm{H} 2$. In addition, the moderator on the main effect (step 5) was transformed through residual-centering by multiplying the coopetition activities and competitive intensity constructs and using a regression model to extract and save their residuals. Residual-centering has been validated throughout the broader marketing literature (Lance, 1988; Cadogan et al., 2009; Story et al., 2015; Disatnik and Sivan, 2016), evidencing that this was a robust tool to use in this investigation.

To emphasise an important point, there are multiple ways that non-linear (inverted U-shaped) and moderation effects can be tested (Sturman, 2003; Cadogan et al., 2009; Story et al., 2015). Yet, there is not a single-agreed method, but rather, a series of varied opinions on how such quantitative techniques should be undertaken (Haans et al., 2016). For clarity, the approach taken in this current study was grounded by earlier research (e.g., Olson et al., 2005; Morgan et al., 2009; Pham et al., 2017). For example, when testing the two research hypotheses, the main effect (coopetition activities) was added to the hierarchical regression model before the non-linear (inverted U-shaped) and moderating effects were tested (i.e., the squared and interaction terms that were transformed through residual-centering). As shown later, there was a lack of support for the main effect, but support existed for the non-linear (inverted U-shaped) and moderating effects. A similar model-testing style has been utilised by other scholars (e.g., Janssens, 2001; Karakaya and Parayitam, 2013; reference withheld). Statistically, it was not important that support did not exist for the main effect (Allison, 1998; Fernhaber and McDougall-Covin, 2014). The reason being was that a diminishing-returns effect was anticipated if businesses engage in excessive degrees of coopetition (building upon Luo et al., 2007; Ang, 2008; Crick, 2019). Instead, the research team were more concerned with the results from the non-linear

\footnotetext{
${ }^{6}$ Mean-centering can be employed to test non-linear (inverted U-shaped) and moderating paths, but such an approach can yield collinearity errors (Echambadi and Hess, 2007). As such, residual-centering was deemed to be a superior tool. The authors express appreciation to an anonymous reviewer for raising this issue.
} 
(inverted U-shaped) and moderating effects, which were significant. Since these paths were significant during the final (nested) stage of the hierarchical regression analysis, $\mathrm{H} 1$ and $\mathrm{H} 2$ were reinforced with statistical evidence (as per Janssens, 2001). Therefore, the approach followed in this paper was underpinned by rigorous evidence ${ }^{7}$.

Eighth, the qualitative stage delved deeper into the meaning behind the quantitative results - with a focus on the underlying mechanisms behind such findings (see Welch et al., 2011; Andriopoulos and Slater, 2013; Sharma et al., 2018). As mentioned earlier, one important area to explore was how competitive intensity can vary domestically and internationally (Kohli and Jaworski, 1990; Jaworski and Kohli, 1993; Grewal and Tansuhaj, 2001; Cadogan et al., 2003) - having the potential to affect the non-linear (inverted U-shaped) relationship between coopetition activities and market performance in several respects. When analysing the interview data, the research team began by manually-coding the transcripts for key and sub-themes relating to "how and why" reasons to explain the quantitative results (as per Miles and Huberman, 1994). Next, the constant comparison technique was utilised. This involved comparing the interview data on a continual basis, so that similarities and commonalities could be identified (Suddaby, 2006). For example, from the 20 sampled businesses, comparison of the data from the first two entities took place against the data from the third firm, then repeated until all 20 companies had been analysed (following Crick, 2018). Further, although theoretical saturation can be difficult to determine (see Beverland and Lindgreen, 2010), the constant comparison technique assisted the research team to identify when they had reached such a point, whereby, there would be a diminishing-returns effect in collecting more data. Thus, the constant comparison technique served as a data analysis tool, as well as a way to evaluate when enough qualitative data had been collected (Suddaby, 2006; Crick, 2018).

\footnotetext{
${ }^{7}$ The authors are grateful for a point made by an anonymous reviewer for recommending more detail should be provided on the different ways that non-linear (inverted U-shaped) and moderating effects can be tested. The research team were appreciative of the different methods that are at academics' disposal (Sturman, 2003; Cadogan et al., 2009; Story et al., 2015; Haans et al., 2016) and chose certain model-testing procedures that were underpinned by earlier investigations (e.g., Aiken and West, 1991; Allison, 1998; Janssens, 2001; Karakaya and Parayitam, 2013; Fernhaber and McDougallCovin, 2014; reference withheld). In short, the quantitative techniques used to test the research hypotheses and control paths were robust and appropriate to achieve the research objective.
} 


\section{Reliability and validity}

Assessment of reliability was through the Cronbach's alpha coefficients $(\alpha)$ of the final operationalisations (internal consistency). As the final scales were above 0.70, the research team deemed the measures as being reliable (Churchill Jr., 1979; Peterson, 1994). Evaluation of validity was in different capacities. Face validity was addressed via pre-testing the electronic survey with a sample of knowledgeable academics $(n=10)$ and practitioners $(\mathrm{n}=15)$ (Reynolds and Diamantopoulos, 1998; reference withheld). Moreover, a check for face validity involved an informant quality scale (adapted from Katsikeas et al., 2006; Hultman et al., 2009) to measure the extent to which the respondents were qualified to participate in this investigation. Assessment of convergent validity was by the final operationalisations having high factor loadings, relatively low error variances, and significant $t$-values during the confirmatory factor analysis (Cadogan et al., 2008). Additionally, evaluation of convergent validity was by having CRs greater than 0.60 and AVEs exceeding 0.50 (Bottger $e t$ al., 2017). Content validity was evaluated by using several established operationalisations to capture the latent variables within the conceptual framework (Peter, 1981). Testing for discriminant validity was by squaring the phi matrix correlations (accessed from LISREL 9.30) and comparing them against the AVEs (Fornell and Larcker, 1981). As the highest squared phi matrix correlation (0.64) was less than the lowest AVE (0.68), discriminant validity is likely to exist within the empirical findings.

\section{Common method variance}

The electronic survey was designed in a way that would maximise the engagement of the respondents (Lindell and Whitney, 2001). This included using a mixture of scale types, colour schemes, and making the instrument as concise as possible (Podsakoff et al., 2003). Additionally, assurance took place with the respondents that their names would rest with the members of the research team and coded to hide their identities (MacKenzie and Podsakoff, 2012). Afterwards, utilisation of the marker variable technique occurred as follows. First, the marker variable was the informant quality scale (adapted from Katsikeas et al., 2006; Hultman et al., 2009), a construct that was theoretically unrelated to any other within the study's conceptual framework (Williams $e t$ al., 2010). The informant quality scale had a mean of 5.80, a SD of 0.95 , and a variance of 0.90 , making it an appropriate construct to test for common method variance. Second, through SPSS 23, the bivariate correlations between the latent variables were processed before a partial correlation matrix was produced, containing the 
same constructs, but controlling for the marker variable (Podsakoff et al., 2003). Third, the differences between the two correlation matrices were analysed, for which the average difference was very small $(r=0.00)$, suggesting that common method variance was highly-unlikely to have biased the statistical results (following Lindell and Whitney, 2001; Story et al., 2015).

As a supplementary statistical technique used to check for evidence of common method variance, the research team conducted Harman's (1967) single-factor test. Using SPSS 23, all multi-item measurement scales were inputted into an exploratory factor analysis model with a principal components analysis extraction and a varimax rotation (Peterson, 2000). Then, alongside the KMO test of sampling adequacy (0.65) and Bartlett's test of sphericity $\left(\chi^{2}=1,833.11 ; d f=325\right.$; Sig. $\left.=0.00\right)$, recording of the amount of variance explained by each factor took place (Bloch et al., 2003). The general rule is that if a single-factor emerges from the model - or one component explains more the $50 \%$ of the overall variance, common method variance exists within the data (Mattila and Enz, 2002). This current study involved the extraction of nine factors - with no evidence of a general (bias) factor. Furthermore, the largest component explained $10.46 \%$ of the exploratory factor analysis model's overall variance $(84.76 \%)$. Therefore, this additional evidence indicated that the data were unaffected by a common method factor (Lings et al., 2014). While criticism exists for Harman's (1967) single-factor test (Chang et al., 2010; reference withheld), the previously mentioned marker variable technique was a more robust tool to check for evidence of common method variance, for which no concerns were raised.

\section{Credibility and trustworthiness in the qualitative study}

The research team concentrated on semi-structured interviews with key decision-makers to supplement the core quantitative findings (Welch et al., 2011; Andriopoulos and Slater, 2013; Sharma et al., 2018). That said, attempts were made to collect secondary data (like via websites and reports) to obtain different sources of data for corroboration purposes (Miles and Huberman, 1994). Although the benefits of computer software to analyse qualitative data are well known (Sinkovics and Alfoldi, 2012), the data were manageable via manual coding to allow the researchers to get "close" to the data. First, empirical quotes maximised the interviewees' voices to avoid miscommunicating practitioner discourse (bracketing) (Tosey et al., 2014). Second, utilisation of the previously mentioned qualitative data analysis techniques took place to obtain a richer understanding of 
the in-depth information and not depend on a single-tool (Suddaby, 2006). Third, theory underpinned the qualitative stage, so that the research team could concentrate on the key, rather than peripheral issues via a process of progressive focusing ${ }^{8}$ (Stake, 2010). Such theory linked with the study's research objective, as well as resource-based theory and the relational view. The statistical results follow in the next section.

\section{Statistical results}

The bivariate correlation coefficients (and descriptive statistics) were produced to examine the relationships between the constructs within the conceptual framework (Table 5).

[Insert Table 5 about here]

Then, using SPSS 23, the research team ran a scatterplot, modelling the relationship between coopetition activities and market performance (Figure 3). The scatterplot revealed that a non-linear (potentially inverted U-shaped) link would better capture the shape of the association (see Allison, 1999). That is, the datapoints were clustered in the centre of the scatterplot, indicating the possibility of a non-linear (inverted U-shaped) as subsequently tested in the hierarchical regression analysis.

\section{[Insert Figure 3 about here]}

To fully-test the complexities of the conceptual framework, utilisation took place of the final stage of the hierarchical regression analysis. As described earlier, more accurate results were yielded once all the latent variables nested within the model, as opposed to the earlier stages of the hierarchical regression analysis. Regarding H1, coopetition activities had a non-linear (inverted U-shaped) relationship with market performance $(\beta=-0.05 ; t=-1.94)$. Therefore, support existed for this component of the conceptual framework. Concerning H2, it was proposed that competitive intensity positively moderates the non-linear (inverted Ushaped) relationship between coopetition activities and market performance. Nevertheless, while a significant moderating effect was found, it was negative $(\beta=-0.10 ; t=-1.82)$. Figure 4 refers to the non-linear (inverted

\footnotetext{
${ }^{8}$ Progressive focusing is a "systematic narrowing and refinement of the research focus during fieldwork to accommodate highly-unique and specific issues" (Sinkovics and Alfoldi, 2012, pp. 818-819). In this current study, the research team used progressive focusing to sift through the interview transcripts for the pertinent issues associated with the results from the research hypotheses. It was especially important for in-depth examples to be utilised to understand the underlying mechanisms behind the quantitative results. The authors appreciate the recommendation of an anonymous reviewer to describe the use of progressive focusing.
} 
U-shaped) relationship between coopetition activities and market performance under low-degrees and highdegrees of competitive intensity. In short, the statistical results indicated that "too little" or "too much" of coopetition activities are harmful for market performance. In other words, instead of there being a positive (linear) relationship between coopetition activities and market performance, there is more likely to be a diminishing-returns effect. Also, competitive intensity negatively moderated this non-linear (inverted Ushaped) effect. In addition, mixed support existed for the control paths.

\section{[Insert Figure 4 about here]}

Further, in each regression model, a high amount of variance was explained (as per the adjusted $\mathrm{R}^{2}$ values) (Table 6). Indeed, the $\mathrm{R}^{2}$ values increased between each stage of the hierarchical regression analysis. This signifies that the addition of these independent variables across the different steps contributed to explaining the variance of the outcome variable (namely, market performance). In fact, relative to the $\Delta F$-statistic (3.29), the $\Delta \mathrm{R}^{2}(0.01)$ was significant during the final (nested) stage of the hierarchical regression analysis. Specifically, the significant change statistics highlighted that the relationship between coopetition activities and market performance was non-linear (inverted U-shaped) and was negatively moderated by competitive intensity ${ }^{9}$. The findings from the qualitative stage follow in the next section.

\section{[Insert Table 6 about here]}

\section{Qualitative findings}

The organisations that participated in the qualitative stage were mixed, in terms their size, age, and degree of internationalisation (Appendix 3). As such, the research team were fortunate to have access to a rich dataset to explore the explanations behind the quantitative results. Such results indicated that coopetition activities have

\footnotetext{
${ }^{9}$ As a point of clarity, the main effect (coopetition activities) was negative and non-significant during the final (nested) stage of the hierarchical regression analysis $(\beta=-0.02 ; t=-0.20)$. However, since the non-linear (inverted U-shaped) and moderating effects were significant, there is evidence to indicate that such results should be supported. That is, as already noted, there are various ways that non-linear (inverted U-shaped) and moderating effects can be tested (Sturman, 2003; Cadogan et al., 2009; Story et al., 2015; Haans et al., 2016), but there is not a single-agreed approach. The methods used in this current paper have been used in earlier research (see Janssens, 2001; Karakaya and Parayitam, 2013). As such, this aspect of the model-testing stage was driven by earlier (robust) work. Furthermore, as stressed throughout this article, the research team expected that a non-linear (inverted U-shaped) relationship exists between coopetition activities and market performance (as per Luo et al., 2007; Ang, 2008; Crick, 2019). Consequently, it was of no concern that there was no support for the main effect (Janssens, 2001; Fernhaber and McDougall-Covin, 2014; reference withheld). Rather, it was more important that the non-linear (inverted U-shaped) and moderating effects were significant (Allison, 1999). The authors would like to express gratitude to an anonymous reviewer for their suggestions on the hierarchical regression analysis.
} 
a non-linear (inverted U-shaped) relationship with market performance - providing support for H1. The interviewees elaborated on a range of issues pertaining to why "too little" or "too much" coopetition is harmful for market performance. Regarding "too little" coopetition, all 20 interviewees suggested that if they do not collaborate with their competitors, they risk struggling to survive within their markets - due to the dangers of possessing an insufficient volume of resources and capabilities. It was important that some knowledge-sharing existed regarding wine tasting to stop a single (rogue) firm producing poor-quality wine that negatively affected customer perceptions of all others within a regional cluster. This meant that there were industry-wide motives for firms engaging in coopetition strategies. Importantly, "too little" coopetition appeared to influence firms' resource-disadvantages (and the dangers of competing with an individualistic business model), indicating that coopetition was required to meet the conditions needed to compete within an industry. Outside of that specific illustration, some representative quotes of "too little" coopetition were:

[...] I suppose that if we didn't share equipment and that kind of thing with our rivals, it'd be hard to cope with the pressures of this industry (Firm 2).

[...] collaboration is important to us. If we didn't work with our competitors, I suspect that we'd go under (Firm 7).

[...] I depend on borrowing equipment from neighbouring vineyards and wineries... I also need to ask them for information... I couldn't survive without these folks (Firm 13).

[...] I've known smaller vineyards and wineries in this area that have operated on their own and haven't had anything to do with the rest of us... Most of them struggle to do well without being a team player (Firm 16).

[...] I collaborate left, right, and centre. It's vital that I can access harvesting tools, information about the wine industry, promotional advice, and so on. If I didn't do any of this, I wouldn't be in business (Firm 20).

Following on, all interviewees highlighted some of the dangers associated with engaging in "too much" coopetition. They provided reasons that included losing critical information (like knowledge about opportunities with distributors), creating tensions with their competitors (especially conflict and power imbalances regarding adhering to reciprocal agreements), and struggling to separate the paradoxical forces of cooperativeness and competitiveness. In the latter case, the qualitative findings supplemented the view that coopetition can be unbalanced by firms engaging in excessive degrees of such activities. In other words, the qualitative findings indicated that coopetition activities are likely to improve market performance, but only to a fixed point, meaning that companies should attempt to engage in an "optimal-level" of coopetition to mitigate such negative consequences. Since a non-linear (inverted U-shaped) relationship existed between coopetition 
activities and market performance (supporting H1), the qualitative data provided supplementary evidence that there is a diminishing-returns effect at play. Some illustrations of "too much" coopetition were:

[...] there have been times where I've suspected that other vineyards and wineries have stolen my ideas. It's really annoyed me, as I thought that I could trust them (Firm 1).

[...] you've got to be very careful when you're getting close to certain competitors. Some are great folks, but if you give them half a chance, they'll try to take customers away from you (Firm 8).

[...] I've made friends through cooperating with competitors, but I've also lost friends... People often show their true colours when there's money involved (Firm 14).

[...] it's difficult to know when enough is enough and when is the best time to think on your own two feet... Collaboration is amazing, but I have no desire to tell other people [rivals] the intricate details of my business (Firm 15).

[...] you've got to remember that these people are competing for the same customers as you are. It's a fierce world out there. So, be collaborative and accommodating, but if you take it too far, all hell breaks loose (Firm 19).

As mentioned earlier, support did not exist for $\mathrm{H} 2$, instead, with a negative, but significant moderating effect. Specifically, it was anticipated that the non-linear (inverted U-shaped) relationship between coopetition activities and market performance becomes greater in magnitude as competitive intensity increases. The reason was that as markets become more competitive, organisations have increased opportunities to engage in coopetition strategies. An expectation existed that higher-degrees of competitiveness facilitate more rivals with whom to share resources and capabilities. Furthermore, it was proposed that competitive intensity allows firms to be more selective regarding the competing businesses that they work with to achieve mutually beneficial performance outcomes. Therefore, with a negative moderation effect, it was important to explore the in-depth reasons behind this counter-intuitive result.

To emphasise an important point, during the hypothesis development, it was acknowledged that two schoolsof-thought surround the competitive business environment (including competitive intensity) positively or negatively impacting the coopetition paradox. From the qualitative findings, all interviewees indicated that competitive intensity might exhibit different effects on the performance outcomes of coopetition strategies. They highlighted that under certain circumstances, increased competition can benefit them, as it provides them with more opportunities to engage in effective (performance-driving) coopetition strategies (including working with rivals in complementary product-markets, as well as those located within a close geographic proximity). This suggests that although there were several downsides of the competitive business environment (as 
discussed below), it had various benefits for improving market performance from coopetition strategies. Thus, the conceptualisations underpinning $\mathrm{H} 2$ were relevant, as competitive intensity had some advantages for coopetition-oriented organisations. Some illustrative quotes were:

[...] it's important to have competitors in easy reach to access advice, equipment, tools, labourers, and so on... In rural parts of the country, it's a lot harder for businesses to perform well, as they depend on their own stuff to be successful (Firm 12).

[...] if I lived and worked in an isolated wine region, I wouldn't be collaborating, which would probably mean that I wouldn't have vital equipment... Without all that, my sales and profits would be poor (Firm 20).

Nonetheless, there was more qualitative evidence to suggest that competitive intensity negatively impacts the non-linear (inverted U-shaped) link between coopetition activities and market performance. All 20 interviewees highlighted that the business environment, including competitive intensity, is complex. Specifically, there are domestic-level and international-level competitive factors affecting the relationship between coopetition activities and market performance. While the coopetition construct is related to the Yin and Yang concept (as discussed later, since practitioners did not use this discourse), it is important to note that the paradoxical forces of cooperativeness and competitiveness vary domestically and internationally. By appreciating that competitive intensity can affect businesses domestically and internationally (in terms of their product-market strategies), the research team could examine the reasons that a negative moderating effect was found in the non-linear (inverted U-shaped) link between coopetition activities and market performance. At a domestic-level, competitive intensity is less likely to affect coopetition in the sector, as the firms were more cooperative than competitive. They needed tourists to visit their vineyards and wineries to buy products and services at cellar doors and other aspects of their business models, like cafés and restaurants; hence, mutually beneficial reciprocal arrangements existed. At an international-level, the 20 interviewees suggested that they are more likely to be competitive than cooperative with their rivals due to often limited opportunities in certain markets, typically via distributors - where supply outstrips demand.

Again, although some scholars have argued that the competitive business environment can help the performance outcomes of coopetition activities, in this current investigation, more qualitative evidence leaned towards the negative forces at play. This was especially pertinent for the wine producers that had higher export ratios, as the importance of overseas markets to such firms' business models (rather than domestic tourism) 
was greater. Put another way, competitive intensity is a complex construct and affects the non-linear (inverted U-shaped) relationship between coopetition activities and market performance in different respects. In this current study, it appears that international-level competitiveness is more likely to unbalance the coopetition paradox than domestic-level competitiveness. In a domestic setting, businesses might be able to simultaneously cooperate and compete for mutually beneficial outcomes for firms in their region (cluster). However, in an international arena, rivalrous behaviours will probably be greater in certain sectors than the magnitude of collaborative activities, as rivals compete for limited distribution opportunities. Put another way, with increased competitiveness, there can be various coopetition-oriented tensions, like conflict, power imbalances, and opportunities that can negatively impact the coopetition paradox's link with market performance. Thus, the qualitative data were effective for explaining the counter-intuitive result behind H2. Some illustrative quotes are as follows:

[...] I suppose that here in New Zealand, we have enough customers interested in Kiwi wine labels and we want to get tourists to our region. However, when we're exporting and we're up against the powerhouses [large established vineyards and wineries] in Europe and the United States, let alone our own competing New Zealand brands, it's a lot fiercer (Firm 3).

[...] on the world stage, New Zealand vineyards and wineries are significantly disadvantaged by the more established wine-producers in Europe, North America, and South America. So, when it comes to collaboration, that all goes out of the window and it's every man for himself (Firm 6).

[...] in New Zealand, it's easy to cooperate and compete, as there are still ways to sell your wine to restaurants, bars, clubs, and pubs... Internationally, it's a whole different game... When I'm selling my wine overseas, I do everything within my power to stand out within the market to get distributor agreements (Firm 12).

[...] as the New Zealand wine industry has expanded this has made it difficult to know who we can work with and who we can trust. If a distributor will take just one wine label from a region, we sometimes have to share the expense of going overseas with a firm from a different region so it is not direct competition (Firm 17).

Lastly, although the interviewees did not refer explicitly to the Yin and Yang concept (an academic term), all described via practitioner discourse how the role of competitive intensity can unhinge these paradoxical forces. Additionally, all interviewees stressed how it is fundamental to manage the interplay between cooperation and competition and not least via trust in collaborating with complementary rivals. For example, the previously alluded to joint promotions with firms producing different varietals of wine, so overseas distributors do not have to choose only one of the brands from those engaged in coopetition, but potentially, those from each of the competitors. Again, competitive intensity affects the non-linear (inverted U-shaped) relationship between 
coopetition activities and market performance in different respects - depending on whether it is viewed as a domestic or international construct. Some illustrative quotes pertaining to the Yin and Yang concept were:

[...] it's a balancing act. In one breath, we are buddies and happy to collaborate, but in another breath, we're rivals. It's super important to know how to trade-off any friendliness against being competitors (Firm 1).

[...] it can be very difficult to cooperate and compete, not least of which guessing when competitive actions take over... Actions speak louder than words and we've become the victims of trusting people [rival companies] that we probably shouldn't have (Firm 4).

[...] over time, we've got pretty good at balancing any cooperation we do against any competition, but all it takes if someone [a rival firm] to change that (Firm 11).

[...] if you're sharing information, equipment, tools, and that kind of stuff, you've got to realise that these people could be screwing you over, taking your customers, and so on. Experience counts a long way and we've got pretty good at knowing who we can trust (Firm 15).

[...] we cooperate, we compete, and we try to balance them, but that's not always possible. Sometimes, others [competitors] can surprise you and change the game (Firm 18).

In short, these qualitative findings explained the underlying mechanisms behind the quantitative results. Most notably, the semi-structured interviews highlighted the reasons driving the negative moderation effect of competitive intensity in the non-linear (inverted U-shaped) relationship between coopetition activities and market performance. It is vital to note that competitive intensity is a complex construct and affects organisations in different respects (domestically versus internationally). It appeared that competitive intensity can affect the non-linear (inverted U-shaped) relationship between coopetition activities and market performance in positive and negative ways. A positive example was providing firms with opportunities to engage in effective (performance-driving) forms of coopetition strategies (with rivals in similar productmarkets and within a close geographic proximity). That said, most companies suggested that competitive intensity is a negative force that can unhinge the delicate coopetition paradox (and the associated Yin and Yang concept). Despite some academics noting the merits of the competitive business environment on the coopetition paradox, there is even more reason that firms must carefully manage the interplay between cooperation and competition. Otherwise, coopetition-oriented organisations might experience certain harmful effects on their market performance, driven by conflict, power imbalances, and opportunistic behaviours (among other tensions). Hence, the qualitative findings reinforced the somewhat counter-intuitive result behind H2. Indeed, such qualitative evidence related to the themes of the relational view and resource-based theory. 
Thus, these findings were connected to the earlier conceptualisations (and underpinning theories). The study's discussion follows in the next section.

\section{Discussion}

A body of knowledge exists concerning the performance-enhancing benefits of engaging in coopetition activities, such as accessing new resources, capabilities, and opportunities that would not exist under individualistic business models (Rindfleisch and Moorman, 2003; Ritala et al., 2014; Czakon and Czernek, 2016; Velu, 2016). Certain research highlights that a linear (positive) link exists between coopetition activities and company performance (Ritala, 2012; Bouncken and Kraus, 2013; Estrada et al., 2016; Hannah and Eisenhardt, 2018). However, some studies have suggested that a non-linear (inverted U-shaped) relationship exists between coopetition activities and market performance (Luo et al., 2007; Ang, 2008; Crick, 2019). Consequently, no agreement exists whether coopetition is always a performance-driving strategy - or if there is a diminishing-returns effect. Moreover, prior to this investigation, relatively little research had been conducted on the moderators that might affect the coopetition - company performance relationship (Ritala, 2012; Bengtsson et al., 2016; Shu et al., 2017; Hoffmann et al., 2018; Crick, 2019). Therefore, this current study built upon the latter conceptualisations to investigate the nature of the relationship between coopetition activities and market performance - non-linear (inverted U-shaped) effects under the moderating role of competitive intensity.

Coopetition strategies relate to the Yin and Yang concept to highlight that assuming potential tensions are managed, the paradoxical forces of cooperativeness and competitiveness can be complementary and allow firms to improve their performance (Chen, 2008; Raza-Ullah et al., 2014; Mattsson and Tidstrom, 2015; Gnyawali et al., 2016; Stadtler and Van Wassenhove, 2016). Thus, guided by resource-based theory and the relational view (Hunt and Morgan, 1995; Dyer and Singh, 1998; Lavie, 2006; Barney, 2018; Dyer et al., 2018), this current investigation utilised the Yin and Yang concept to identify whether there will be any harmful effects on market performance if the interplay between cooperation and competition is unbalanced. In contributing to knowledge, the results indicated that coopetition activities have a non-linear (inverted Ushaped) relationship with market performance. That is, if firms engage in "too little" coopetition, as a result of 
their resource-disadvantages, they might struggle to survive within their markets, with an insufficient volume of resources and capabilities (Rusko, 2011; Ritala et al., 2014; Granata et al., 2018; reference withheld). Yet, with "too much" coopetition, businesses could experience a range of problems, such as tensions with their rivals and not knowing when to engage in an "optimal-level" of coopetition. They should build trust and collaborate with complementary industry rivals to acquire new resources, capabilities, and opportunities (Bouncken and Kraus, 2013; Felzensztein et al., 2014), but not to the extent that they damage such relationships and yield certain negative consequences (Luo et al., 2007; Ang, 2008; Ritala and Hurmelinna-Laukkanen, 2013; Crick, 2019).

The Yin and Yang concept, when applied to coopetition strategies, suggests that firms are most likely to improve their performance from such activities when the paradoxical forces of cooperativeness and competitiveness are stable (Chen, 2008; Raza-Ullah et al., 2014; Mattsson and Tidstrom, 2015; Gnyawali et al., 2016; Stadtler and Van Wassenhove, 2016). Therefore, the Yin and Yang concept can be infused into the non-linear (inverted $\mathrm{U}$-shaped) relationship between coopetition activities and market performance. The reason being is that such a link depicts that "too little" or "too much" coopetition is harmful for market performance, encouraging companies to manage the interplay between cooperation and competition to an "optimal-level" to avoid such outcomes (Crick, 2019). Moreover, the Yin and Yang concept is a helpful tool to highlight how the paradoxical forces of cooperativeness and competitiveness can be unbalanced - with harmful performance consequences for organisations. Therefore, as well as extending existing knowledge on the performance outcomes of coopetition activities, new explanations are offered on the coopetition paradox and how competitive intensity could unhinge such a balance (building upon Bengtsson et al., 2016). Furthermore, with support from the quantitative and qualitative data originating from the New Zealand wine industry, new evidence has emerged on how this Eastern philosophy applies to Western contexts.

Additionally, it was expected that competitive intensity positively moderates the non-linear (inverted Ushaped) relationship between coopetition activities and market performance. The reasoning for this research hypothesis was that as markets become more competitive, organisations not only have increased scope to collaborate with their industry rivals, but more importantly, can become more selective, in terms of which firms that they share resources and capabilities with (Felzensztein et al., 2012; Geldes et al., 2017; Granata et 
al., 2018). However, the results indicated that competitive intensity negatively moderates the non-linear (inverted U-shaped) relationship between coopetition activities and market performance. According to Crick (2019), the competitive business environment can affect the link between coopetition and company performance in various capacities. In fact, existing theory suggests that higher-levels of competitive intensity can affect the balance between the paradoxical forces of cooperativeness and competitive and create tensions (like conflict and power imbalances) between such rival entities (see Tidstrom, 2009; Bengtsson et al., 2016; Czakon and Czernek, 2016; Cui et al., 2018). Additionally, the qualitative findings reinforced that debate surrounding how competitive intensity can have different (positive and negative) moderating effects on the non-linear (inverted U-shaped) relationship between coopetition activities and market performance (following Crick, 2019). From the mixed methods results, it is inferred that competitive intensity is more likely to be a hindering force, than a helpful one and especially in overseas markets.

Attribution of this finding relates to the complex nature of the competitive business environment affecting organisations domestically and internationally (Kohli and Jaworski, 1990; Jaworski and Kohli, 1993; Grewal and Tansuhaj, 2001; Cadogan et al., 2003; Virtanen and Kock, 2016). Following the qualitative findings, unique insights suggest that if businesses compete for a combination of domestic and international markets, the interplay between cooperation and competition varies. In domestic contexts, firms might have more scope to simultaneously cooperate and compete with their rivals, such as the tourism aspect of business models in this current study with reciprocal arrangements, like cross-referrals. However, if firms are competing against a larger group of rivals (from numerous countries), the changing dynamic environment forces organisations to increase their competitive behaviours over any degree of collaboration. An illustration in this article involved competing brands for the same distributor, who in contrast, might be interested in different varietals of wine, influencing firms to operate with complementary rivals. This paper emphasises the delicate balance surrounding the interplay between cooperation and competition across product-markets (Chen, 2008; RazaUllah et al., 2014; Mattsson and Tidstrom, 2015; Gnyawali et al., 2016; Stadtler and Van Wassenhove, 2016; Cui et al., 2018). The complex nature of the competitive business environment helps to address the priormentioned debate regarding whether competitive intensity positively or negatively impacts the coopetition paradox (following Crick, 2019). In fact, such findings reinforce earlier work examining the dark-side of 
coopetition strategies (e.g., Luo et al., 2007; Ang, 2008; Raza-Ullah et al., 2014; Bouncken et al., 2018; reference withheld).

As an illustration, higher-levels of competitiveness could drive various tensions between coopetition partners, like conflict, power imbalances, and opportunistic behaviours (Luo et al., 2007; Ang, 2008; Ritala and Hurmelinna-Laukannen, 2013; Park et al., 2014; Tidstrom, 2014; Cui et al., 2018). Thus, new evidence has emerged on how competitive intensity negatively impacts the coopetition paradox. Again, the findings signify that the Yin and Yang concept of coopetition is an Eastern philosophy that has applications to Western contexts, not least of which with new evidence surrounding the need to balance the coopetition paradox. Additionally, this current study has contributed to the growing knowledge linked to the contingencies that could affect the relationship between coopetition activities and company performance (Ritala, 2012; Bengtsson et al., 2016). In fact, the moderators that could affect the link between coopetition activities and company performance are under-researched. Consequently, this current study's results revealed that the non-linear (inverted U-shaped) relationship between coopetition activities and market performance is contingent on the degree of competitive intensity. As such, researchers should appreciate the potential for moderating factors when conceptualising the nature of the relationship between coopetition activities and company performance (Ang, 2008; Shu et al., 2017). Indeed, Hoffmann et al. (2018) argued that the coopetition - company performance relationship is complex - with the potential for non-linear (inverted U-shaped) and moderating effects. This paper has contributed to this view by recognising the complexities of the coopetition - company performance relationship, across product-markets, including how competitive intensity could be a contingency at play within such a link.

Regarding the control paths, there was no support for the relationship between firm size and market performance, with a negative, but non-significant link. This result indicates that larger organisations, with more resources and capabilities, do not necessarily have a greater scope to obtain higher-levels of company performance than smaller businesses (contrary to Hunt and Morgan, 1995; Hooley et al., 1998; Ekeledo and Sivakumar, 2004; Kumar et al., 2011; Barney, 2014). In respect of firm age and market performance, there was a negative, but non-significant relationship. This result highlights that as companies become older, their heritage does not necessarily assist them to increase their market performance (contrary to Ramaswami et al., 2009; Vorhies et al., 2011; Mohr and Batsakis, 2014). Alternatively, industry experience was highly related to 
market performance, with a positive and significant relationship. It follows that if entrepreneurs and their employees possess more experience (an organisational capability) in their sectors, they can utilise it to perform well in their product-markets (supporting Noble and Gruca, 1999; Purani and Sahadev, 2008). The qualitative findings illustrated how experience enables owner-managers to form relationships with complementary rivals, whereby, trust develops over time.

The dimensions of the entrepreneurial orientation construct provided some interesting results. That is, innovativeness, proactiveness, autonomy, and competitive aggressiveness had non-significant links with market performance. In contrast, risk-taking had a negative, but significant relationship with market performance; indeed, the qualitative stage offered illustrations regarding the management of risk in respect of coopetition strategies. These results suggest that the respective dimensions of the entrepreneurial orientation construct have varying degrees of importance for companies (building upon Lumpkin and Dess, 1996; Matsuno et al., 2002; Rauch et al., 2009; Chen et al., 2012; Sundqvist et al., 2012; Boso et al., 2013; Jin and Cho, 2018). Lastly, degree of internationalisation had a weak, but non-significant link with market performance. This result indicates that internationalised companies do not always obtain higher-levels of business performance - in comparison to predominately domestic-oriented firms (to some extent challenging Axinn, 1988; Katsikeas et al., 2000; Kropp et al., 2006; Dubiel et al., 2018). Nevertheless, the influence of management teams' respective objectives are important (see Spence and Crick, 2006; reference withheld); hence, the qualitative findings offered insights regarding product-market strategies in line with objectives, with some owner-managers focusing on domestic wine sales and tourism in comparison to others whose interest involved wine sales overseas.

A further contribution relates to theoretical perspectives used to underpin this study. The integration of resource-based theory and the relational view takes place in earlier studies to highlight issues associated with the coopetition construct (Lavie, 2006; Dyer et al., 2018; Crick, 2019). In one respect, the resource-based view examines how organisational resources and capabilities can yield higher-levels of company performance (Hunt and Morgan, 1995; Fahy and Smithee, 1999; Hooley et al., 2005; Menguc and Auh, 2006; Ngo and O'Cass, 2012; Barney, 2014; Tan and Sousa, 2015). In another respect, the relational view evaluates the importance of high-quality networks between businesses (Gronroos, 1997; Lado et al., 1997; Dyer and Singh, 1998). Linking with coopetition strategies, in this current study, the resource-based view helped to explain how companies 
align competitors' resources and capabilities with their own tangible and intangible assets. The associated relational view focused on the quality of such relationships and the role of trust, in terms of the cooperative and competitive dynamics at play. In other words, resource-based theory and the relational view explained the variance of the complex link between coopetition activities and market performance. This included the moderating role of competitive intensity in the above-mentioned relationship, which can be attributed to the developments made to resource-based theory and the relational view (Priem and Butler, 2001; Lavie, 2006; Dyer et al., 2018).

Moreover, this investigation has contributed to the under-developed research pertaining to coopetition in an international arena. Prior to this paper, coopetition had been linked with internationalised firms, but typically, such research applied to multinational corporations (Luo, 2005; Luo and Tung, 2007; Ranganathan et al., 2018), rather than smaller businesses (Chetty and Wilson, 2003; Virtanen and Kock, 2016; Felzensztein et al., 2019). This study found that the complex nature of competitive intensity (affecting domestic and international product-markets) influences the performance consequences of coopetition activities for smaller-sized firms. Thus, owner-managers of internationally-oriented organisations should be aware that different forms of rivalry can distort the interplay between cooperation and competition. Domestic, vis-à-vis, international rivalry is argued to contribute to the Yin and Yang concept underpinning coopetition activities. With higher-levels of competitive intensity, the Yin and Yang concept could be unbalanced. From this study's results, extensions are made to the work of Chen (2008), Raza-Ullah et al. (2014), Mattsson and Tidstrom (2015), Gnyawali et al. (2016), and Stadtler and Van Wassenhove (2016), in terms of the applications of the Yin and Yang concept. This yielded improved conceptualisations and empirical evidence on how this Eastern philosophy applies in Western contexts. The moderating role of competitive intensity supplements the environmental contingencies that have featured in earlier studies using conceptualisations from resource-based theory and the relational view (Cadogan et al., 2003; Kumar et al., 2011; Girod and Whittington, 2017; Dyer et al., 2018). The investigation is concluded as follows.

\section{Conclusions}

\section{Summary}

The objective of this study was to utilise the Yin and Yang concept to explain the non-linear (inverted Ushaped) relationship between coopetition and company performance under the moderating role of competitive 
intensity. After analysing the statistical data for all major checks of reliability, validity, and common method variance (and some supplementary qualitative data), the following five conclusions are made. First, it is concluded that coopetition activities have a non-linear (inverted U-shaped) relationship with market performance. Second, contrary to expectations, it is also concluded that competitive intensity negatively moderates the non-linear (inverted U-shaped) relationship between coopetition activities and market performance. Third, a further conclusion is that the Yin and Yang concept helps to explain how the paradoxical forces of cooperativeness and competitiveness need to balance for coopetition activities to improve market performance. Fourth, it is concluded that this current investigation has addressed two schools-of thought pertaining to the impact of the competitive business environment (specifically, competitive intensity) on the relationship between coopetition activities and market performance. Fifth, a final conclusion is that if markets are highly competitive, the Yin and Yang of coopetition is especially at risk of being out of balance, unless effective management of relationships occurs across product-market strategies. That is, it follows that as competitiveness increases, coopetition activities can be harmful for market performance due to the larger chance of inter-firm tensions (conflict, power imbalances, and opportunistic behaviours).

\section{Practitioner implications}

In addition to its theoretical contribution, this investigation has several implications for practitioners. First, owner-managers of organisations should appreciate the benefits of engaging in coopetition strategies, like acquiring new resources, capabilities, and opportunities that would not exist under individualistic business models. However, firms should collaborate with their competitors to an "optimal-level", but not to an excessive extent, as there could be negative effects on their performance. Second, owner-managers should be aware that if markets are highly competitive, their coopetition partners might exhibit rivalrous behaviours that outweigh any cooperative activities. As such, practitioners should build trust and be careful about working with complementary rivals whose product-market strategies offer win/win opportunities in coopetition relationships. Third, and on a related issue, if owner-managers collaborate with their competitors, the cooperative and competitive dynamics can vary across product-markets. In the context of this current study, within domestic markets, firms might be able to simultaneously cooperate and compete with rival entities due to the need for reciprocal arrangements as part of a tourism-related business model (wine sales at cellar doors, 
cafés, restaurants, etc.). However, in an international area, they can experience more competitiveness than cooperativeness because of limited demand from distributors for rival brands of the same wine varietal. Hence, a need exists for caution when engaging in coopetition strategies. Similar contextual implications are important for practitioners in other sectors linked to their own product-markets strategies. In short, while there are numerous advantages of coopetition, the firms involved must be cautious of the potential negative consequences of such strategies.

\section{Limitations and avenues for future research}

While this investigation has extended the international marketing literature, future research can address certain limitations. First, this study utilised empirical data from one sector, namely, the New Zealand wine industry. Despite this being a suitable empirical context to obtain the necessary data in a non-Eastern setting to test the research hypotheses and control paths (also, for the qualitative investigation), future research should employ multi-industry samples to ensure that the results are generalisable. Second, this current study relied on singlesource data during the quantitative stage. In future investigations, researchers should use high-quality measures from multiple sources, such as operationalising market performance through archival data. Third, the sample size used in this article was relatively small $(n=101)$, even though it accounted for a respectable response rate (13.91\%). Therefore, future research should collect larger samples to yield generalisable results. Fourth, it would be interesting to undertake cross-national comparisons, using empirical data from culturally and economically similar countries (like Australian, British, American, and Canadian data). Subsequently, once such cross-country comparisons take place, researchers should conduct further studies in culturally and economically distant countries (such as South African, Ghanaian, and Saudi Arabian data). This way, the international marketing literature can be strengthened with more information on how Asian philosophies apply (or do not apply) to non-Asian nations. In closing, these limitations do not pose serious concerns, but rather, provide ample scope to build upon the themes of this paper to strengthen the marketing literature. 


\section{References}

Aiken, L.S. and West, S.G. (1991), Multiple Regression: Testing and Interpreting Interactions, Sage Publications Limited, Thousand Oaks: CA.

Allison, P.D. (1999), Multiple Regression: A Primer, Sage Publications Limited, Thousand Oaks: CA.

Andriopoulos, C. and Slater, S. (2013), "Exploring the landscape of qualitative research in international marketing: two decades of IMR", International Marketing Review, Vol. 30 No. 4, pp. 384-412.

Ang, S.H. (2008), "Competitive intensity and collaboration: impact on firm growth across technological environments", Strategic Management Journal, Vol. 29 No. 10, pp. 1057-1075.

Armstrong, J.S. and Overton, T.S. (1977), "Estimating non-response bias in mail surveys", Journal of Marketing Research, Vol. 14 No. 3, pp. 396-402.

Arslan, B. (2018), "The interplay of competitive and cooperative behavior and differential benefits in alliances", Strategic Management Journal, Vol. 39 No. 12, pp. 3222-3246.

Axinn, C.N. (1988), “Export performance: do managerial perceptions make a difference?”, International Marketing Review, Vol. 5 No. 2, pp. 61-71.

Bahadir, S.C., Bharadwaj, S. and Parzen, M. (2009), "A meta-analysis of the determinants of organic sales growth”, International Journal of Research in Marketing, Vol. 26 No. 4, pp. 263-275.

Barney, J.B. (1991), "Firm resources and sustained competitive advantage", Journal of Management, Vol. 17 No. 1, pp. 99-120.

Barney, J.B. (2001), "Is the resource-based view a useful perspective for strategic management research? Yes", Academy of Management Review, Vol. 26 No. 1, pp. 41-56.

Barney, J.B. (2014), "How marketing scholars might help address issues in resource-based theory", Journal of the Academy of Marketing Science, Vol. 42 No. 1, pp. 24-26.

Barney, J.B. (2018), "Why resource-based theory's model of profit appropriation must incorporate a stakeholder perspective", Strategic Management Journal, Vol. 39 No. 13, pp. 3305-3325.

Bengtsson, M. and Kock, S. (1999), "Cooperation and competition in relationships between competitors in business networks", Journal of Business \& Industrial Marketing, Vol. 14 No. 3, pp. 178-194.

Bengtsson, M. and Kock, S. (2000), "Coopetition in business networks: to cooperate and compete simultaneously”, Industrial Marketing Management, Vol. 29 No. 5, pp. 411-426.

Bengtsson, M. and Kock, S. (2014), "Coopetition - quo vadis? Past accomplishments and future challenges", Industrial Marketing Management, Vol. 43 No. 2, pp. 180-188.

Bengtsson, M. and Raza-Ullah, T. (2016), "A systematic review of research on coopetition: toward a multilevel understanding”, Industrial Marketing Management, Vol. 57 No. 1, pp. 23-39.

Bengtsson, M., Raza-Ullah, T. and Vanyushyn, V. (2016), "The coopetition paradox and tension: the moderating role of coopetition capability", Industrial Marketing Management, Vol. 53 No. 1, pp. 1930.

Beverland, M. and Lindgreen, A. (2010), "What makes a good case study? A positivist review of qualitative case research published in Industrial Marketing Management, 1971-2006", Industrial Marketing Management, Vol. 39 No. 1, pp. 56-63.

Blesa, A. and Ripolles, M. (2008), "The influence of marketing capabilities on economic international performance", International Marketing Review, Vol. 26 No. 6, pp. 651-673.

Bloch, P.H., Brunel, F.F. and Arnould, T.J. (2003), "Individual differences in the centrality of visual product aesthetics: concept and measurement", Journal of Consumer Research, Vol. 29 No. 4, pp. 551-565. 
Boso, N., Story, V.M. and Cadogan, J.W. (2013), "Entrepreneurial orientation, market orientation, network ties, and performance: study of entrepreneurial firms in a developing economy", Journal of Business Venturing, Vol. 28 No. 6, pp. 708-727.

Bottger, T., Rudolph, T., Evanschitzky, H. and Pfrang, T. (2017), "Customer inspiration: conceptualization, scale development, and validation", Journal of Marketing, Vol. 81 No. 6, pp. 116-131.

Bouncken, R.B. and Fredrich, V. (2016), "Learning in coopetition: alliance orientation, network size, and firm types", Journal of Business Research, Vol. 69 No. 5, pp. 1753-1758.

Bouncken, R.B. and Kraus, S. (2013), "Innovation in knowledge-intensive industries: the double-edged sword of coopetition", Journal of Business Research, Vol. 66 No. 10, pp. 2060-2070.

Bouncken, R.B., Fredrich, V., Ritala, P. and Kraus, S. (2018), "Coopetition in new product development alliances: advantages and tensions for incremental and radical innovation", British Journal of Management, Vol. 29 No. 3, pp. 391-410.

Bowman, C. and Ambrosini, V. (2003), "How the resource-based and the dynamic capability views of the firm inform corporate-level strategy", British Journal of Management, Vol. 14 No. 4, pp. 289-303.

Brandenburger, A.M. and Nalebuff, B.J. (1996), Co-opetition, Doubleday Dell Publishing Group Inc., New York: NY.

Cadogan, J.W., Cui, C.C. and Li, E.K.Y. (2003), "Export market-oriented behavior and export performance: the moderating roles of competitive intensity and technological turbulence", International Marketing Review, Vol. 20 No. 5, pp. 493-513.

Cadogan, J.W., Diamantopoulos, A. and Siguaw, J.A. (2002), "Export market-oriented activities: their antecedents and performance consequences", Journal of International Business Studies, Vol. 33 No. 3, pp. 615-626.

Cadogan, J.W., Kuivalinen, O. and Sundqvist, S. (2009), "Export market-oriented behavior and export performance: quadratic and moderating effects under differing degrees of market dynamism and internationalization”, Journal of International Marketing, Vol. 17 No. 4, pp. 71-89.

Cadogan, J.W., Paul, N.J., Salminen, R.T., Puumalainen, K. and Sundqvist, S. (2001), "Key antecedents to export market-oriented behaviors: a cross-national empirical examination", International Journal of Research in Marketing, Vol. 18 No. 3, pp. 261-282.

Cadogan, J.W., Souchon, A.L. and Procter, D.B. (2008), "The quality of market-oriented behaviors: formative index construction”, Journal of Business Research, Vol. 61 No. 12, pp. 1263-1277.

Cadogan, J.W., Sundqvist, S., Puumalainen, K. and Salminen, R.T. (2012), "Strategic flexibilities and export performance: the moderating roles of export market-oriented behavior and the export environment", European Journal of Marketing, Vol. 46 No. 10, pp. 1418-1452.

Cadogan, J.W., Sundqvist, S., Salminen, R.T. and Puumalainen, K. (2005), "Export marketing, interfunctional interactions, and performance consequences", Journal of the Academy of Marketing Science, Vol. 33 No. 4, pp. 520-535.

Chai, L., Li, J., Clauss, T. and Tangpong, C. (2019), "The influences of interdependence, opportunism and technology uncertainty on interfirm coopetition", Journal of Business \& Industrial Marketing, Vol. 34 No. 5, pp. 948-964.

Chang, S.J., van Witteloostuijn, A. and Eden, L. (2010), "Common method variance in international business research”, Journal of International Business Studies, Vol. 41 No. 2, pp. 178-184.

Charters, S., Fountain, J. and Fish, N. (2009), "You felt like lingering... experiencing real service at the winery tasting room", Journal of Travel Research, Vol. 48 No. 1, pp. 122-134.

Chen, M-J. (2001), Inside Chinese Business: A Guide for Managers Worldwide, Harvard Business School Press, Boston: MA. 
Chen, M-J. (2008), "Reconceptualizing the competition-cooperation relationship: a trans-paradox perspective", Journal of Management Inquiry, Vol. 17 No. 4, pp. 288-304.

Chen, Y-C., Li, P-C. and Evans, K.R. (2012), "Effects of interaction and entrepreneurial orientation on organizational performance: insights into market-driven and market-driving", Industrial Marketing Management, Vol. 41 No. 6, pp. 1019-1034.

Chetty, S.K. and Wilson, H.I.M. (2003), “Collaborating with competitors to acquire resources”, International Business Review, Vol. 12 No. 1, pp. 61-81.

Churchill Jr., G.A. (1979), “A paradigm for developing better measures of marketing constructs”, Journal of Marketing Research, Vol. 16 No. 1, pp. 64-73.

Combe, I.A. and Greenley, G.E. (2004), "Capabilities for strategic flexibility: a cognitive content framework", European Journal of Marketing, Vol. 38 Nos. 11/12, pp. 1456-1480.

Contractor, N.S., Wasserman, S. and Faust, K. (2006), "Testing multi-theoretical, multi-level hypotheses about organizational networks: an analytic framework and empirical example", Academy of Management Review, Vol. 31 No. 3, pp. 681-703.

Crick, J.M. (2018), "The facets, antecedents and consequences of coopetition: an entrepreneurial marketing perspective”, Qualitative Market Research: An International Journal, Vol. 21 No. 2, pp. 253-272.

Crick, J.M. (2019), "Moderators affecting the relationship between coopetition and company performance", Journal of Business \& Industrial Marketing, Vol. 34 No. 2, pp. 518-531.

Cui, V., Yang, H. and Vertinsky, I. (2018), "Attacking your partners: strategic alliances and competition between partners in product-markets", Strategic Management Journal, Vol. 39 No. 12, pp. 3116-3139.

Czakon, W. and Czernek, K. (2016), "The role of trust-building mechanisms in entering into network coopetition: the case of tourism networks in Poland", Industrial Marketing Management, Vol. 57 No. 1, pp. 64-74.

Czakon, W., Klimas, P. and Mariani, M. (2019), "Behavioral antecedents of coopetition: a synthesis and measurement scale", Long Range Planning (Forthcoming).

Dahl, J. (2014), "Conceptualizing coopetition as a process: an outline of change in cooperative and competitive interactions", Industrial Marketing Management, Vol. 43 No. 2, pp. 272-279.

Diamantopoulos, A. and Cadogan, J.W. (1996), "Internationalizing the market orientation construct: an indepth interview approach", Journal of Strategic Marketing, Vol. 4 No. 1, pp. 23-52.

Disatnik, D. and Sivan, L. (2016), "The multicollinearity illusion in moderated regression analysis", Marketing Letters, Vol. 27 No. 2, pp. 403-408.

Dubiel, A., Banerjee, S., Ernst, H. and Subramaniam, M. (2018), "International-market-information use across new-product-development stages: antecedents and performance implications", International Marketing Review, Vol. 35 No. 5, pp. 760-784.

Dyer, J.H. and Singh, H. (1998), "The relational view: cooperative strategy and sources of inter-organizational competitive advantage", Academy of Management Review, Vol. 23 No. 4, pp. 660-679.

Dyer, J.H., Singh, H. and Hesterly, W.S. (2018), "The relational view revisited: a dynamic perspective on value creation and value capture", Strategic Management Journal, Vol. 39 No. 12, pp. 3140-3162.

Echambadi, R. and Hess, J.D. (2007), "Mean-centering does not alleviate collinearity problems in moderated multiple regression models", Marketing Science, Vol. 26 No. 3, pp. 438-445.

Estrada, I., Faems, D. and de Faria, P. (2016), "Coopetition and product innovation performance: the role of internal knowledge-sharing mechanisms and formal knowledge protection mechanisms", Industrial Marketing Management, Vol. 53 No. 1, pp. 56-65. 
Ekeledo, I. and Sivakumar, K. (2004), "International market entry mode strategies of manufacturing firms and service firms: a resource-based perspective", International Marketing Review, Vol. 21 No. 1, pp. 68101.

Fahy, J. and Smithee, A. (1999), "Strategic marketing and the resource-based view of the firm", AMS Review, Vol. 10 No. 1, pp. 1-30.

Fang, T. (2006), "Negotiation: the Chinese style", Journal of Business \& Industrial Marketing, Vol. 21 No. 1, pp. 50-60.

Fang, T. (2010), “Asian management research needs more self-confidence: reflection on Hofstede (2007) and beyond", Asia Pacific Journal of Management, Vol. 27 No. 1, pp. 155-170.

Felzensztein, C., Deans, K.R. and Dana, L-P. (2019), "Small firms in regional clusters: local networks and internationalization in the Southern Hemisphere", Journal of Small Business Management, Vol. 57 No. 2, pp. 496-516.

Felzensztein, C., Gimmon, E. and Aqueveque, C. (2012), "Clusters or un-clustered industries? Where interfirm marketing cooperation matters", Journal of Business \& Industrial Marketing, Vol. 27 No. 5, pp. 392-402.

Felzensztein, C., Stringer, C., Benson-Rea, M. and Freeman, S. (2014), "International marketing strategies in industrial clusters: insights from the Southern Hemisphere", Journal of Business Research, Vol. 67 No. 5, pp. 837-846.

Fernhaber, S.A. and McDougall-Covin, P.P. (2014), "Is more always better? Risk trade-offs among internationalizing new ventures", European Business Review, Vol. 26 No. 5, pp. 406-420.

Fletcher, R. and Fang, T. (2006), "Assessing the impact of culture on relationship creation and network formation in emerging Asian markets", European Journal of Marketing, Vol. 40 Nos. 3/4, pp. 430-446.

Fornell, C. and Larcker, D.F. (1981), "Structural equation models with unobservable variables and measurement error: algebra and statistics", Journal of Marketing Research, Vol. 18 No. 3, pp. 382-388.

Freeman, S., Edwards, R. and Schroder, B. (2006), "How smaller born-global firms use networks and alliances to overcome constraints to rapid internationalization", Journal of International Marketing, Vol. 14 No. 3, pp. 33-63.

French, M.J. and Cadogan, J.W. (2011), "Export market-oriented processes and export performance: quadratic and moderated relationships", in Melewar, T.C. and Gupta, S. (Eds), Strategic International Marketing: An Advanced Perspective, Palgrave Macmillan, London: England, pp. 201-223.

Gao, H., Ren, M. and Miao, Q. (2018), “Toward a Yin-Yang balancing perspective of relational (Guanxi) gatekeeping in international exchange relationships in China”, Journal of International Marketing, Vol. 26 No. 2, pp. 22-42.

Geldes, C., Heredia, J., Felzensztein, C. and Mora, M. (2017), "Proximity as determinant of business cooperation for technological and non-technological innovations: a study of an agribusiness cluster", Journal of Business \& Industrial Marketing, Vol. 32 No. 1, pp. 167-178.

Gerbing, D.W. and Anderson, J.C. (1988), "An updated paradigm for scale development incorporating unidimensionality and its assessment", Journal of Marketing Research, Vol. 25 No. 2, pp. 186-192.

Girod, S.J.G. and Whittington, R. (2017), "Reconfiguration, restructuring and firm performance: dynamic capabilities and environmental dynamism", Strategic Management Journal, Vol. 38 No. 5, pp. 11211133.

Gnyawali, D.R. and Charleton, T.R. (2018), "Nuances in the interplay of competition and cooperation: towards a theory of coopetition", Journal of Management, Vol. 44 No. 7, pp. 2511-2534.

Gnyawali, D.R., Madhavan, R., He, J. and Bengtsson, M. (2016), "The competition-cooperation paradox in inter-firm relationships: a conceptual framework", Industrial Marketing Management, Vol. 53 No. 1, pp. 7-18. 
Granata, J., Lasch, F., Le Roy, F. and Dana, L-P. (2018), "How do micro-firms manage coopetition? A study of the wine sector in France", International Small Business Journal, Vol. 36 No. 3, pp. 331-355.

Grewal, R. and Tansuhaj, P. (2001), "Building organizational capabilities for managing economic crisis: the role of market orientation and strategic flexibility", Journal of Marketing, Vol. 65 No. 2, pp. 67-80.

Gronroos, C. (1997), "Value-driven relational marketing: from products to resources and competencies", Journal of Marketing Management, Vol. 13 No. 5, pp. 407-419.

Haans, R.F.J., Pieters, C. and He, Z-L. (2016), “Thinking about U: theorizing and testing U- and inverted Ushaped relationships in strategy research", Strategic Management Journal, Vol. 37 No. 7, pp. 1177-1195.

Hagen, B., Zucchella, A. and Ghauri, P.N. (2019), "From fragile to agile: marketing as a key driver of entrepreneurial internationalization”, International Marketing Review, Vol. 36 No. 2, pp. 260-288.

Hannah, D.P. and Eisenhardt, K.M. (2018), "How firms navigate cooperation and competition in nascent ecosystems", Strategic Management Journal, Vol. 39 No. 12, pp. 3163-3192.

Harman, H.H. (1967), Modern Factor Analysis, second edition, University of Chicago Press, Chicago: IL.

Henderson, P.W., Cote, J.A., Leong, S.M. and Schmitt, B. (2003), "Building strong brands in Asia: selecting the visual components of image to maximize brand strength", International Journal of Research in Marketing, Vol. 20 No. 4, pp. 297-313.

Hoffmann, W., Lavie, D., Reuer, J.J. and Shiplov, A. (2018), "The interplay of competition and cooperation", Strategic Management Journal, Vol. 39 No. 12, pp. 3033-3052.

Hooley, G.J., Broderick, A.J. and Moller, K. (1998), "Competitive positioning and the resource-based view of the firm", Journal of Strategic Marketing, Vol. 6 No. 2, pp. 97-116.

Hooley, G.J., Greenley, G.E., Cadogan, J.W. and Fahy, J. (2005), "The performance impact of marketing resources", Journal of Business Research, Vol. 58 No. 1, pp. 18-27.

Hultman, M., Robson, M.J. and Katsikeas, C.S. (2009), "Export product strategy fit and performance: an empirical investigation", Journal of International Marketing, Vol. 17 No. 4, pp. 1-23.

Hunt, S.D. and Morgan, R.M. (1995), "The comparative advantage theory of competition", Journal of Marketing, Vol. 59 No. 2, pp. 1-15.

Hunt, S.D., Sparkman Jr., R.D. and Wilcox, J.B. (1982), "The pre-test in survey research: issues and preliminary findings", Journal of Marketing Research, Vol. 19 No. 2, pp. 269-273.

Hurley, R.F. and Hult, G.T.M. (1998), "Innovation, market orientation, and organizational learning: an integration and empirical examination", Journal of Marketing, Vol. 62 No. 3, pp. 42-54.

Jancic, Z. and Zabkar, V. (2002), "Impersonal vs. personal exchanges in marketing relationships”, Journal of Marketing Management, Vol. 18 Nos. 7/8, pp. 657-671.

Janssens, O. (2001), "Fairness perceptions as a moderator in the curvilinear relationships between job demands, and job performance and job satisfaction", Academy of Management Journal, Vol. 44 No. 5, pp. 1039-1050.

Jaworski, B.J. and Kohli, A.K. (1993), "Market orientation: antecedents and consequences", Journal of Marketing, Vol. 57 No. 3, pp. 53-70.

Jin, B. and Cho, H.J. (2018), "Examining the role of international entrepreneurial orientation, domestic market competition, and technological and marketing capabilities on SME's export performance", Journal of Business \& Industrial Marketing, Vol. 33 No. 5, pp. 585-598.

Kanter, R.M. (1994), “Collaborative advantage: the art of alliances”, Harvard Business Review, Vol. 72 No. 4, pp. 96-108.

Karakaya, F. and Parayitam, S. (2013), "Barriers to entry and firm performance: a proposed model and curvilinear relationships", Journal of Strategic Marketing, Vol. 21 No. 1, pp. 25-47. 
Katsikeas, C.S., Leonidou, L.C. and Morgan, N.A. (2000), "Firm-level export performance assessment: review, evaluation, and development", Journal of the Academy of Marketing Science, Vol. 28 No. 4, pp. 493-511.

Katsikeas, C.S., Morgan, N.A., Leonidou, L.C. and Hult, G.T.M. (2016), “Assessing performance outcomes in marketing", Journal of Marketing, Vol. 80 No. 2, pp. 1-20.

Katsikeas, C.S., Samiee, S. and Theodosiou, M. (2006), "Strategy fit and performance consequences of international marketing standardization”, Strategic Management Journal, Vol. 27 No. 9, pp. 867-890.

Kohli, A.K. and Jaworski, B.J. (1990), "Market orientation: the construct, research propositions, and managerial implications", Journal of Marketing, Vol. 54 No. 2, pp. 1-18.

Kozlenkova, I.V., Samaha, S.A. and Palmatier, R.W. (2014), "Resource-based theory in marketing", Journal of the Academy of Marketing Science, Vol. 42 No. 1, pp. 1-21.

Kropp, F., Lindsay, N.J. and Shoham, A. (2006), "Entrepreneurial, market, and learning orientations and international entrepreneurial business venture performance in South African firms", International Marketing Review, Vol. 23 No. 5, pp. 504-523.

Kuivalainen, O., Sundqvist, S., Saarenketo, S. and McNaughton, R. (2012), "Internationalization patterns of small and medium-sized enterprises", International Marketing Review, Vol. 29 No. 5, pp. 448-465.

Kumar, V., Jones, E., Venkatesan, R. and Leone, R.P. (2011), "Is market orientation a source of sustainable competitive advantage or simply the cost of competing?", Journal of Marketing, Vol. 75 No. 1, pp. 1630.

Lado, A.A., Boyd, N.G. and Hanlon, S.C. (1997), "Competition, cooperation, and the search for economic rents: a syncretic model”, Academy of Management Review, Vol. 22 No. 1, pp. 110-141.

Lance, C.E. (1988), "Residual-centering, exploratory and confirmatory moderator analysis, and decomposition of effects in path models containing interactions", Applied Psychological Measurement, Vol. 12 No. 2, pp. 163-175.

Lavie, D. (2006), "The competitive advantage of inter-connected firms: an extension of the resource-based view", Academy of Management Review, Vol. 31 No. 3, pp. 638-658.

Lindell, M.K. and Whitney, D.J. (2001), "Accounting for common method variance in cross-sectional research designs", Journal of Applied Psychology, Vol. 86 No. 1, pp. 114-121.

Lings, I., Durden, G., Lee, N. and Cadogan, J.W. (2014), "Socio-emotional and operational demands on service employees", Journal of Business Research, Vol. 67 No. 10, pp. 2132-2138.

Lumpkin, G.T. and Dess, G.G. (1996), "Clarifying the entrepreneurial orientation construct and linking it to performance", Academy of Management Review, Vol. 21 No. 1, pp. 135-172.

Luo, X., Rindfleisch, A. and Tse, D.K. (2007), "Working with rivals: the impact of competitor alliances on financial performance", Journal of Marketing Research, Vol. 44 No. 1, pp. 73-83.

Luo, Y. (2005), "Toward coopetition within a multinational enterprise: a perspective from foreign subsidiaries", Journal of World Business, Vol. 40 No. 1, pp. 71-90.

Luo, Y. and Tung, R.L. (2007), "International expansion of emerging market enterprises: a springboard perspective", Journal of International Business Studies, Vol. 38 No. 4, pp. 481-498.

MacKenzie, S.B. and Podsakoff, P.M. (2012), "Common method bias in marketing: causes, mechanisms, and procedural remedies", Journal of Retailing, Vol. 88 No. 4, pp. 542-555.

Matsuno, K., Mentzer, J.T. and Ozsomer, A. (2002), "The effects of entrepreneurial proclivity and market orientation on business performance", Journal of Marketing, Vol. 66 No. 3, pp. 18-32.

Mattila, A.S. and Enz, C.A. (2002), "The role of emotions in service encounters", Journal of Service Research, Vol. 4 No. 4, pp. 268-277. 
Mattsson, L-G. and Tidstrom, A. (2015), “Applying the principles of Yin-Yang to market dynamics: on the duality of cooperation and competition", Marketing Theory, 15(3), pp. 347-364.

Menguc, B. and Auh, S. (2006), "Creating a firm-level dynamic capability through capitalizing on market orientation and innovativeness", Journal of the Academy of Marketing Science, Vol. 34 No. 1, pp. 6373 .

Merlo, O. and Auh, S. (2009), "The effects of entrepreneurial orientation, market orientation, and marketing sub-unit influence on firm performance", Marketing Letters, Vol. 20 No. 3, pp. 295-311.

Miles, M.B. and Huberman, A.M. (1994), Qualitative Data Analysis: An Expanded Sourcebook, second edition, Sage Publications Limited, Thousand Oaks: CA.

Miocevic, D. and Morgan, R.E. (2018), "Operational capabilities and entrepreneurial opportunities in emerging market firms: explaining exporting SME growth", International Marketing Review, Vol. 35 No. 2, pp. 320-341.

Mohr, A. and Batsakis, G. (2014), "Intangible assets, international experience and the internationalisation speed of retailers", International Marketing Review, Vol. 31 No. 6, pp. 601-620.

Moorman, C. (1995), "Organizational market information processes: cultural antecedents and new product outcomes", Journal of Marketing Research, Vol. 32 No. 3, pp. 318-335.

Morgan, N.A. (2012), "Marketing and business performance", Journal of the Academy of Marketing Science, Vol. 40 No. 1, pp. 102-119.

Morgan, N.A., Vorhies, D.W. and Mason, C.H. (2009), "Market orientation, marketing capabilities, and firm performance", Strategic Management Journal, Vol. 30 No. 8, pp. 909-920.

Morgan, R.M. and Hunt, S.D. (1994), "The commitment-trust theory of relationship marketing", Journal of Marketing, Vol. 58 No. 3, pp. 20-38.

Nemkova, E., Souchon, A.L. and Hughes, P. (2012), "Export decision-making orientation: an exploratory study", International Marketing Review, Vol. 29 No. 4, pp. 349-378.

New Zealand Winegrowers Association (2018), "Discover our regions", available at: https://www.nzwine.com/en/our-regions/ (accessed 18 December 2018).

Ngo, L.V. and O'Cass, A. (2012), "Performance implications of market orientation, marketing resources, and marketing capabilities", Journal of Marketing Management, Vol. 28 Nos. 1/2, pp. 173-187.

Noble, P.M. and Gruca, T.S. (1999), "Industrial pricing: theory and managerial practice”, Marketing Science, Vol. 18 No. 3, pp. 435-454.

O'Cass, A., Ngo, L.V. and Siahtiri, V. (2015), "Marketing resource-capability complementarity and firm performance in B2B firms", Journal of Business \& Industrial Marketing, Vol. 30 No. 2, pp. 194-207.

Olson, E.M., Slater, S.F. and Hult, G.T.M. (2005), "The performance implications of fit among business strategy, marketing organization structure, and strategic behavior", Journal of Marketing, Vol. 69 No. 3, pp. 49-65.

Park, B.J.R., Srivastava, M.K. and Gnyawali, D.R. (2014), "Walking the tightrope of coopetition: impact of competition and cooperation intensities and balance on firm innovation performance", Industrial Marketing Management, Vol. 43 No. 2, pp. 210-221.

Peng, M.W. and Luo, Y. (2000), "Managerial ties and firm performance in a transition economy: the nature of a micro-macro link", Academy of Management Journal, Vol. 43 No. 3, pp. 486-501.

Peter, J.P. (1981), "Construct validity: a review of basic issues and marketing practices", Journal of Marketing Review, Vol. 18 No. 2, pp. 133-145.

Peterson, R.A. (1994), “A meta-analysis of Cronbach's coefficient alpha”, Journal of Consumer Research, Vol. 21 No. 2, pp. 381-391. 
Peterson, R.A. (2000), "A meta-analysis of variance accounted for and factor loadings in exploratory factor analysis", Marketing Letters, Vol. 11 No. 3, pp. 261-275.

Pham, T.S.H., Monkhouse, L.L. and Barnes, B.R. (2017), “The influence of relational capability and marketing capabilities on the export performance of emerging market firms", International Marketing Review, Vol. 34 No. 5, pp. 606-628.

Podsakoff, P.M., Mackenzie, S.B., Lee, J.Y. and Podsakoff, N.P. (2003), "Common method biases in behavioral research: a critical review of the literature and recommended remedies", Journal of Applied Psychology, Vol. 88 No. 5, pp. 879-903.

Prahalad, C.K. and Hamel, G. (1994), “Strategy as a field of study: why search for a new paradigm?”, Strategic Management Journal, Vol. 15 No. 2, pp. 5-16.

Priem, R.L. and Butler, J.E. (2001), "Is the resource-based view a useful perspective for strategic management research?", Academy of Management Review, Vol. 26 No. 1, pp. 22-40.

Purani, K. and Sahadev, S. (2008), "The moderating role of industrial experience in the job satisfaction, intention to leave relationship: an empirical study among salesmen in India", Journal of Business \& Industrial Marketing, Vol. 23 No. 7, pp. 475-485.

Ramaswami, S.N., Srivastava, R.K. and Bhargava, M. (2009), "Market-based capabilities and financial performance of firms: insights into marketing's contribution to firm value", Journal of the Academy of Marketing Science, Vol. 37 No. 2, pp. 97-116.

Ranganathan, R., Ghosh, A. and Rosenkopf, L. (2018), "Competition-cooperation interplay during multi-firm technology coordination: the effect of firm heterogeneity on conflict and consensus in a technology standards organization", Strategic Management Journal, Vol. 39 No. 12, pp. 3193-3221.

Rauch, A., Wiklund, J., Lumpkin, G.T. and Frese, M. (2009), "Entrepreneurial orientation and business performance: an assessment of past research and suggestions for the future", Entrepreneurship Theory and Practice, Vol. 33 No. 3, pp. 761-787.

Ray, G., Barney, J.B. and Muhanna, W.A. (2004), "Capabilities, business processes, and competitive advantage: choosing the dependent variable in empirical tests of the resource-based view", Strategic Management Journal, Vol. 25 No. 1, pp. 23-37.

Raza-Ullah, T., Bengtsson, M. and Kock, S. (2014), “The coopetition paradox and tension in coopetition at multiple-levels", Industrial Marketing Management, Vol. 43 No. 2, pp. 189-198.

Reid, S.D. (1983), "Firm internationalization, transaction costs and strategic choice", International Marketing Review, Vol. 1 No. 2, pp. 44-56.

Reynolds, N. and Diamantopoulos, A. (1998), "The effect of pre-test method on error detection rates: experimental evidence", European Journal of Marketing, Vol. 32 Nos. 5/6, pp. 480-498.

Rindfleisch, A. and Moorman, C. (2003), "Inter-firm cooperation and customer orientation", Journal of Marketing Research, Vol. 40 No. 4, pp. 421-436.

Ritala, P. (2012), "Coopetition strategy - when is it successful? Empirical evidence on innovation and market performance", British Journal of Management, Vol. 23 No. 3, pp. 307-324.

Ritala, P. and Hurmelinna-Laukkanen, P. (2013), "Incremental and radical innovation in coopetition: the role of absorptive capacity and appropriability", Journal of Product Innovation Management, Vol. 30 No. 1, pp. 154-169.

Ritala, P., Golnam, A. and Wegmann, A. (2014), "Coopetition-based business models: the case of Amazon.com”, Industrial Marketing Management, Vol. 43 No. 2, pp. 236-249.

Rusko, R. (2011), "Exploring the concept of coopetition: a typology for the strategic moves of the Finnish forest industry", Industrial Marketing Management, Vol. 40 No. 2, pp. 311-320. 
Ryan, P., Evers, N., Smith, A. and Andersson, S. (2019), "Local horizontal network membership for accelerated global market reach", International Marketing Review, Vol. 36 No. 1, pp. 6-30.

Sharma, R.R., Sraha, G. and Crick, D. (2018), "Export promotion programmes and the export performance of Ghanaian firms: the mediating role of foreign market attractiveness", International Marketing Review, Vol. 35 No. 4, pp. 661-682.

Shu, C., Jin, J.L. and Zhou, K.Z. (2017), "A contingent view of partner coopetition in international joint ventures", Journal of International Marketing, Vol. 25 No. 3, pp. 42-60.

Sinkovics, R.R. and Alfoldi, E.A (2012), "Progressive focusing and trustworthiness in qualitative research: the enabling role of computer-assisted data analysis software (CAQDAS)", Management International Review, Vol. 52 No. 6, pp. 817-845.

Spence, M. and Crick, D. (2006), "A comparative investigation into the internationalisation of Canadian and UK high-tech SMEs”, International Marketing Review, Vol. 23 No. 5, pp. 524-548.

Stadtler, L. and Van Wassenhove, L.N. (2016), "Coopetition as a paradox: integrative approaches in a multicompany, cross-sector partnership", Organization Studies, Vol. 37 No. 5, pp. 655-685.

Stake, R.E. (2010), Qualitative Research: Studying How Things Work, The Guildford Press, New York: NY.

Story, V.M., Boso, N. and Cadogan, J.W. (2015), "The form of relationship between firm-level product innovativeness and new product performance in developed and emerging markets", Journal of Product Innovation Management, Vol. 32 No. 1, pp. 45-64.

Sturman, M.C. (2003), "Searching for the inverted U-shaped relationship between time and performance: meta-analyses of the experience/performance, tenure/performance, and age/performance relationships", Journal of Management, Vol. 29 No. 5, pp. 609-640.

Styles, C. and Ambler, T. (2003), "The coexistence of transaction and relational marketing: insights from the Chinese business context", Industrial Marketing Management, Vol. 32 No. 8, pp. 633-642.

Suddaby, R. (2006), "From the editors: what grounded theory is not", Academy of Management Journal, Vol. 49 No. 4, pp. 633-642.

Sundqvist, S., Kylaheiko, K., Kuivalainen, O. and Cadogan, J.W. (2012), "Kirznerian and Schumpeterian entrepreneurial-oriented behavior in turbulent export markets", International Marketing Review, Vol. 29 No. 2, pp. 203-219.

Sun Tzu. (1963), The Art of War (translated by Samuel B. Griffith), Oxford University Press, London.

Sun, W. and Price, J.M. (2016), "Implications of marketing capability and research and development intensity on firm default risk", Journal of Marketing Management, Vol. 32 Nos. 1/2, pp. 179-206.

Tan, Q. and Sousa, C.M.P. (2015), "Leveraging marketing capabilities into competitive advantage and export performance", International Marketing Review, Vol. 32 No. 1, pp. 78-102.

The International Organisations of Vine and Wine. (2017), "Global economic viticulture data", available at: http://www.oiv.int/public/medias/5681/en-communiqu-depresse-octobre-2017.pdf (accessed 10 August 2018).

Tidstrom, A. (2009), "Causes of conflict in inter-competitor cooperation", Journal of Business \& Industrial Marketing, Vol. 24 No. 7, pp. 506-518.

Tidstrom, A. (2014), "Managing tensions in coopetition", Industrial Marketing Management, Vol. 43 No. 2, pp. 261-271.

Tosey, P, Lawley, J. and Meese, R. (2014), "Eliciting metaphor through clean language: an innovation in qualitative research", British Journal of Management, Vol. 25 No. 3, pp. 629-646.

Velu, C. (2016), "Evolutionary or revolutionary business model innovation through coopetition? The role of dominance in network markets", Industrial Marketing Management, Vol. 53 No. 1, pp. 124-135. 
Virtanen, H. and Kock, S. (2016), "Tension in coopetition between small- and medium-sized firms", Proceedings of the McGill International Entrepreneurship Conference, Vaasa, Finland.

Vorhies, D.W. and Morgan, N.A. (2005), "Benchmarking marketing capabilities for sustainable competitive advantage”, Journal of Marketing, Vol. 69 No. 1, pp. 80-94.

Vorhies, D.W., Orr, L.M. and Bush, V.D. (2011), "Improving customer-focused marketing capabilities and firm financial performance via marketing exploration and exploitation", Journal of the Academy of Marketing Science, Vol. 39 No. 5, pp. 736-756.

Welch, C., Piekkari, R., Plakoyiannaki, E. and Paavilainen-Mantymaki, E. (2011), "Theorising from case studies: towards a pluralist future for international business research", Journal of International Business Studies, Vol. 42 No. 5, pp. 740-762.

Wiklund, J. and Shepherd, D.A. (2003), "Knowledge-based resources, entrepreneurial orientation, and the performance of small and medium-sized businesses", Strategic Management Journal, Vol. 24 No. 13, pp. 1307-1314.

Williams, L.J., Hartman, N. and Cavazotte, F. (2010), "Method variance and marker variables: a review and comprehensive CFA marker technique", Organizational Research Methods, Vol. 13 No. 3, pp. 477-514.

Zou, S. and Stan, S. (1998), "The determinants of export performance: a review of the empirical literature between 1987 and 1997”, International Marketing Review, Vol. 15 No. 5, pp. 333-356. 
Figure 1. The Yin and Yang concept related to coopetition activities

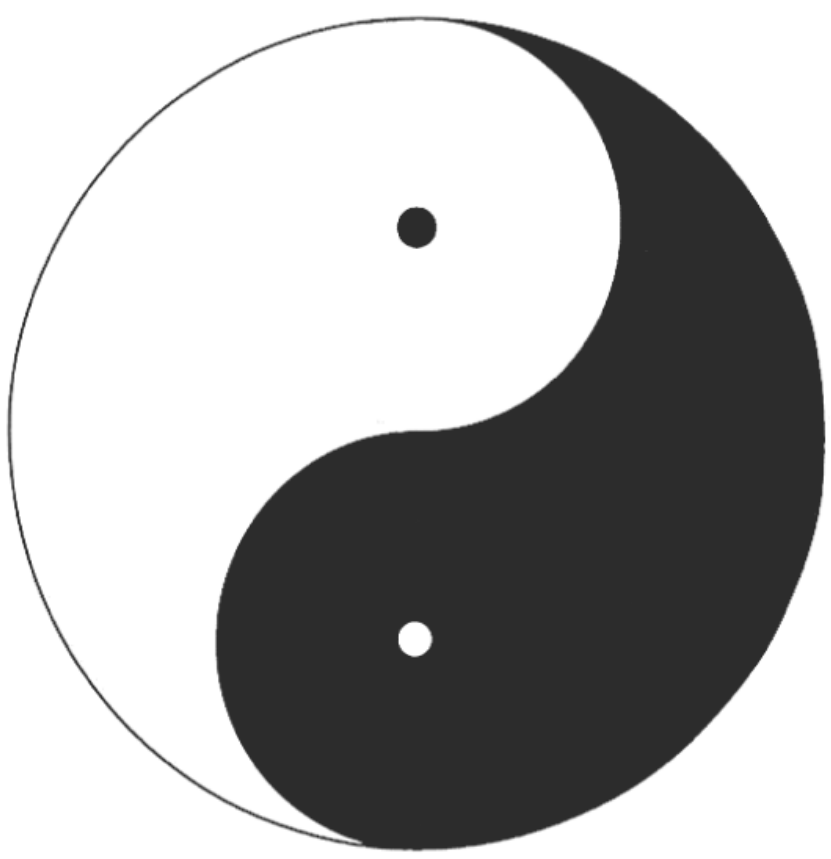

The Yin and Yang of coopetition is characterised by the paradoxical forces of cooperativeness and competitiveness (Chen, 2008; Fang, 2010; Raza-Ullah et al., 2014). The black area represents competitiveness and the white area represents cooperativeness (Fang, 2006; Mattsson and Tidstrom, 2015; Gnyawali et al., 2016; Stadtler and Van Wassenhove, 2016).

Figure 2. Conceptual framework

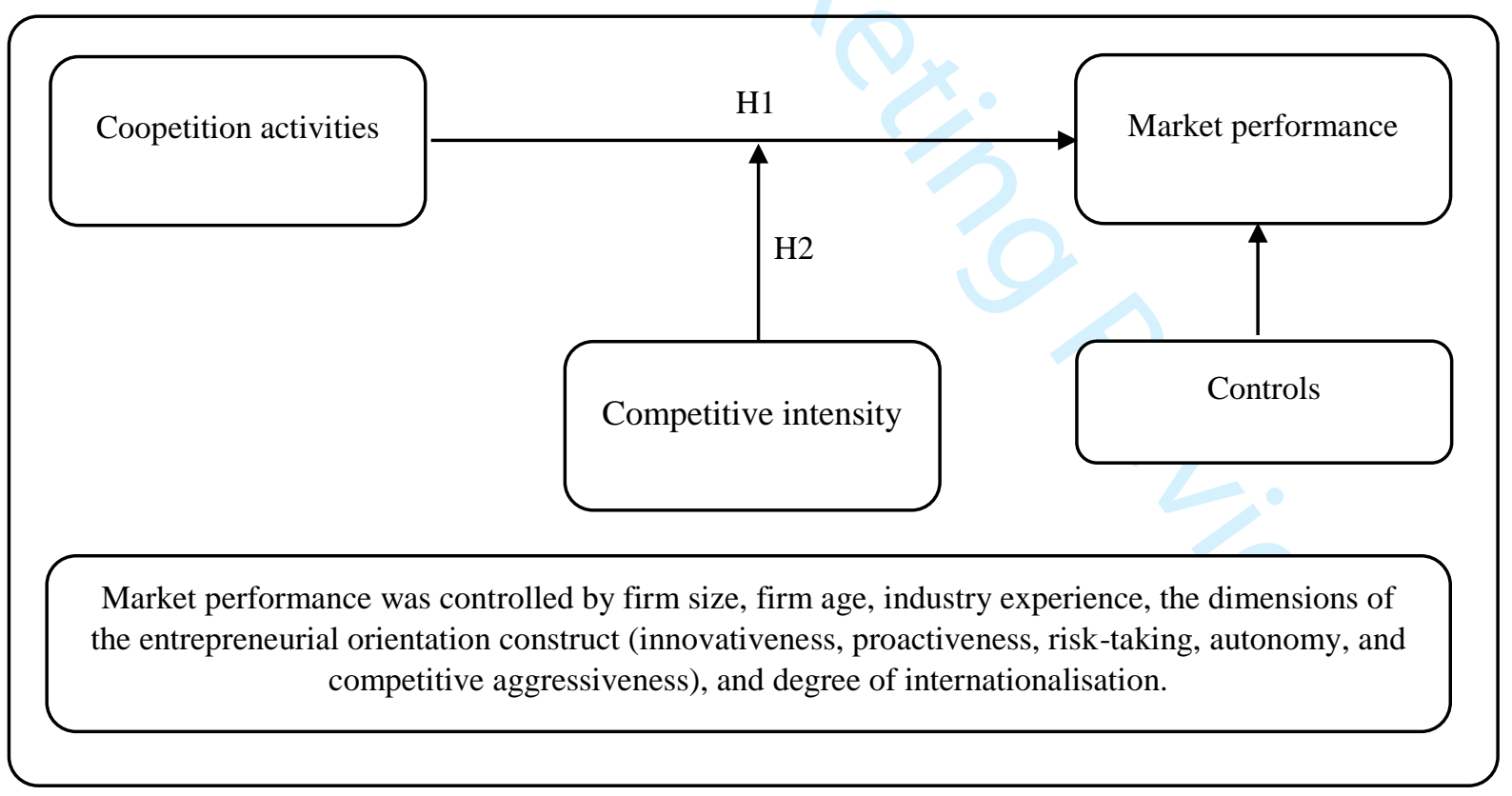


Figure 3. Scatterplot modelling the relationship between coopetition activities and market performance

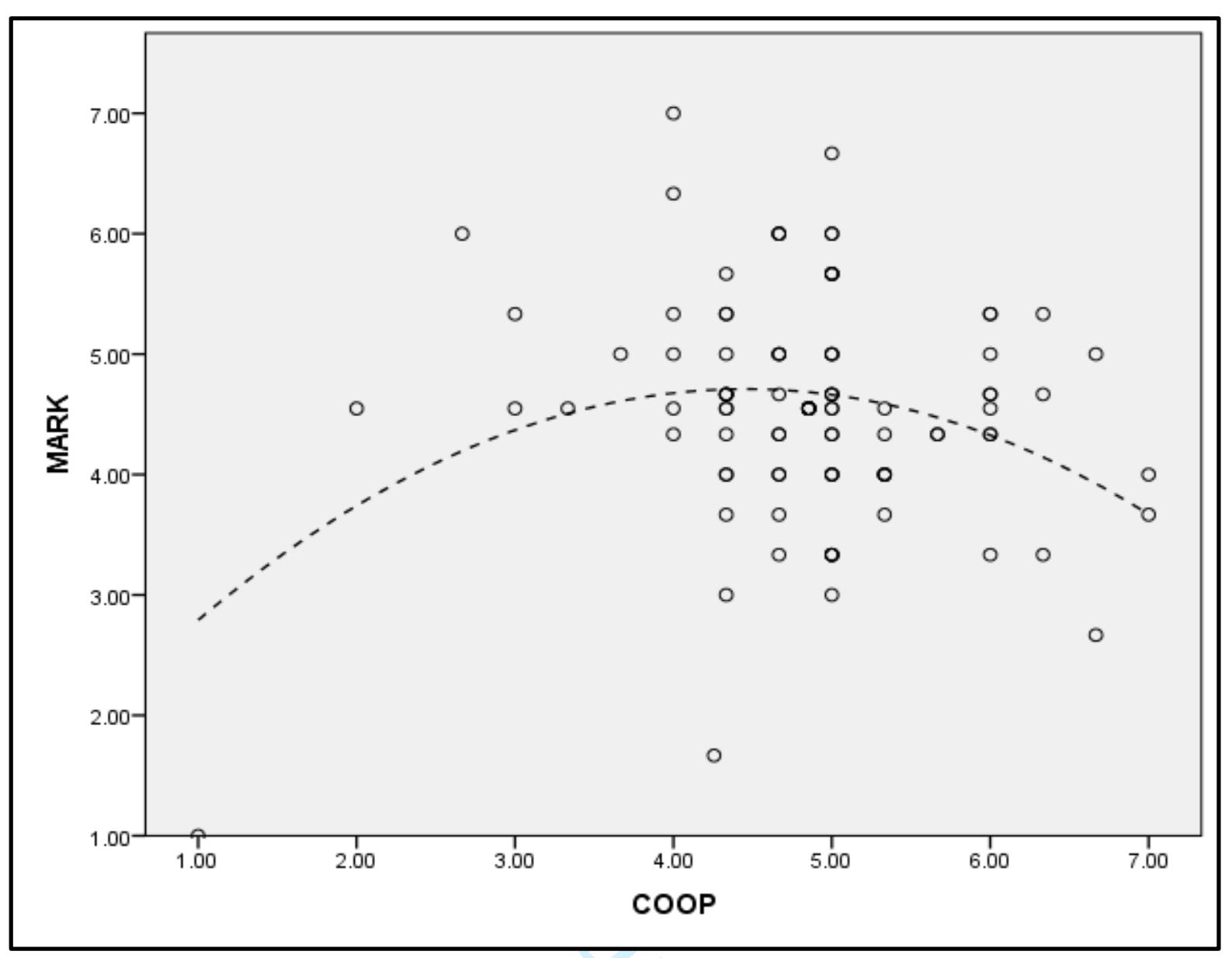

Figure 4. Moderation effects of competitive intensity

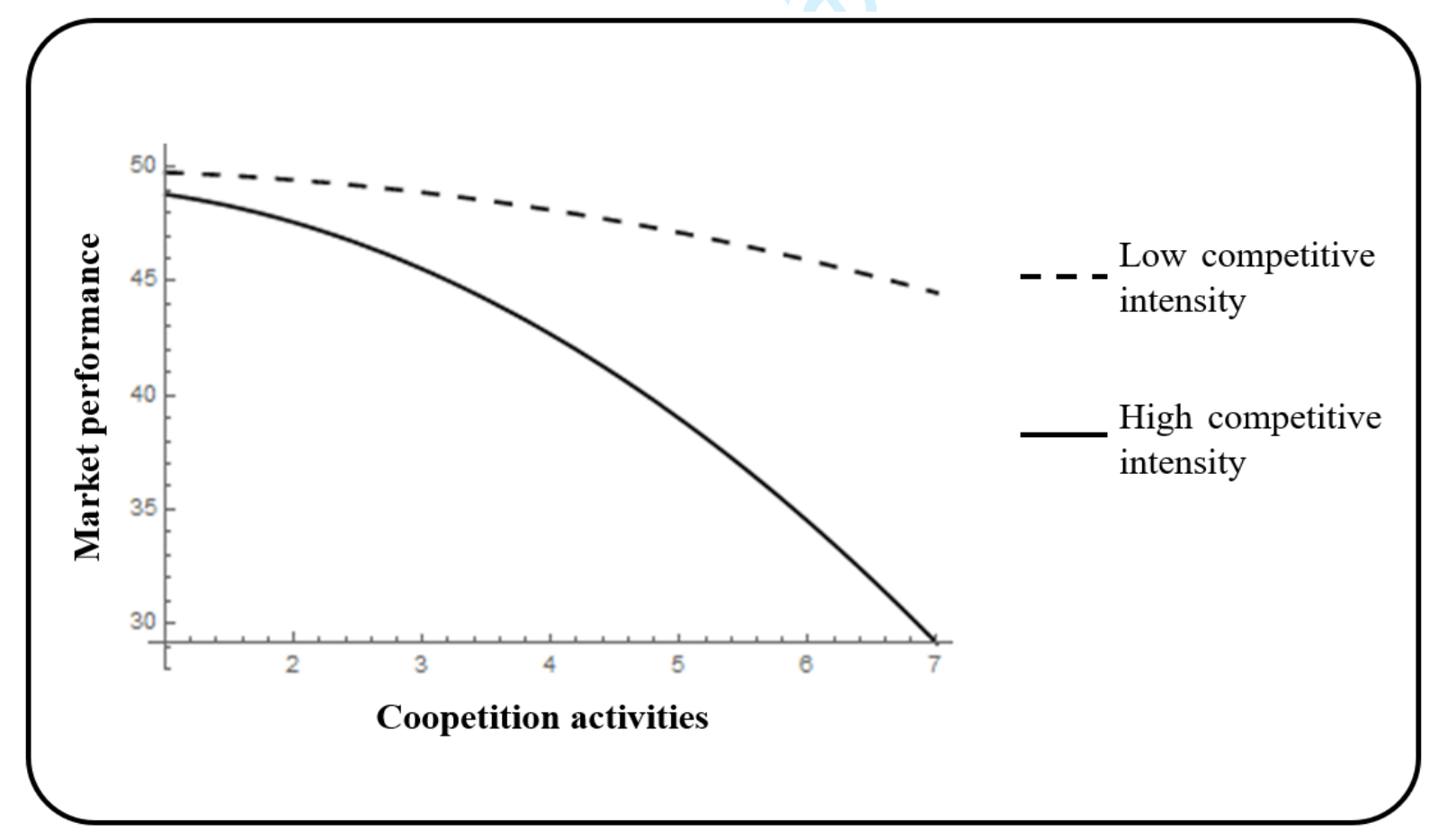


Table 1. Characteristics of the final sample

\begin{tabular}{|l|c|c|c|c|}
\hline Characteristics & Mean & Median & SD & Variance \\
\hline Full-time employees & 13.44 & 5.00 & 27.03 & 730.62 \\
\hline Part-time employees & 12.16 & 5.00 & 23.20 & 538.24 \\
\hline Firm age (years) & 68.95 & 72.00 & 14.42 & 207.82 \\
\hline Industry experience (years) & 18.39 & 18.40 & 10.37 & 107.54 \\
\hline Years in current role & 12.63 & 12.00 & 7.52 & 56.55 \\
\hline Years in current organisation & 14.32 & 12.00 & 9.24 & 85.38 \\
\hline Export ratio (\%) & 27.71 & 19.70 & 26.77 & 716.63 \\
\hline Number of export markets & 8.53 & 8.00 & 11.41 & 130.19 \\
\hline Annual sales (\$NZ millions) & 2.34 & 2.20 & 2.52 & 6.35 \\
\hline
\end{tabular}

Table 2. Exploratory factor analysis model

\begin{tabular}{|c|c|c|c|c|c|c|c|c|c|}
\hline & \multicolumn{9}{|c|}{ Components $^{a}$} \\
\hline Items & 1 & 2 & 3 & 4 & 5 & 6 & 7 & 8 & 9 \\
\hline$\overline{C O O P} \_1$ & 0.78 & -0.11 & 0.10 & -0.14 & 0.04 & 0.06 & 0.07 & -0.17 & 0.01 \\
\hline COOP_2 & 0.89 & -0.05 & 0.00 & 0.07 & -0.02 & -0.11 & 0.05 & 0.01 & -0.05 \\
\hline COOP_3 & 0.87 & -0.12 & -0.12 & 0.08 & 0.04 & 0.01 & -0.04 & 0.13 & -0.09 \\
\hline COOP_4 & 0.85 & -0.19 & -0.02 & 0.00 & -0.08 & -0.09 & -0.04 & 0.13 & -0.11 \\
\hline COMP_1 & -0.10 & 0.84 & -0.03 & -0.07 & -0.10 & 0.06 & -0.01 & -0.06 & -0.05 \\
\hline COMP_2 & -0.16 & 0.88 & 0.04 & -0.03 & 0.02 & -0.07 & -0.03 & -0.06 & -0.08 \\
\hline COMP_3 & -0.21 & 0.65 & -0.11 & 0.33 & -0.06 & 0.04 & 0.05 & 0.12 & 0.11 \\
\hline COMP_4 & 0.01 & 0.89 & -0.04 & 0.19 & -0.10 & 0.14 & -0.05 & -0.07 & 0.04 \\
\hline COMP_5 & -0.08 & 0.83 & -0.11 & 0.02 & 0.11 & 0.08 & 0.09 & -0.05 & -0.08 \\
\hline MARK_1 & 0.00 & 0.04 & 0.90 & 0.08 & 0.11 & 0.03 & 0.06 & 0.17 & 0.11 \\
\hline MARK_2 & -0.01 & -0.04 & 0.90 & 0.04 & 0.00 & -0.01 & 0.10 & 0.16 & 0.04 \\
\hline MARK_3 & -0.04 & -0.12 & 0.88 & 0.09 & -0.04 & 0.04 & 0.20 & 0.11 & -0.04 \\
\hline MARK_4 & 0.08 & -0.13 & 0.72 & 0.31 & -0.01 & -0.06 & 0.03 & 0.06 & 0.10 \\
\hline PRCT_1 & -0.01 & 0.01 & 0.18 & 0.83 & 0.13 & 0.02 & -0.01 & 0.24 & 0.05 \\
\hline PRCT_2 & -0.02 & 0.07 & 0.37 & 0.76 & -0.02 & 0.16 & 0.03 & 0.03 & -0.08 \\
\hline PRCT_3 & 0.02 & 0.03 & -0.01 & 0.81 & -0.06 & 0.12 & -0.15 & 0.20 & 0.08 \\
\hline RISK_1 & -0.08 & -0.11 & 0.11 & -0.10 & 0.87 & 0.06 & 0.09 & 0.18 & 0.03 \\
\hline RISK_2 & 0.05 & 0.04 & -0.01 & 0.03 & 0.91 & 0.13 & 0.08 & 0.03 & -0.04 \\
\hline RISK_3 & -0.01 & 0.04 & -0.04 & 0.09 & 0.88 & 0.13 & 0.06 & 0.14 & 0.00 \\
\hline CAGG_1 & -0.11 & 0.08 & 0.13 & 0.00 & 0.12 & 0.92 & 0.01 & -0.08 & 0.03 \\
\hline CAGG_2 & -0.05 & 0.06 & 0.04 & 0.06 & 0.12 & 0.91 & -0.01 & -0.09 & -0.07 \\
\hline CAGG_3 & -0.08 & 0.02 & -0.03 & 0.06 & 0.06 & 0.89 & 0.00 & -0.10 & -0.03 \\
\hline AUTO_1 & 0.02 & 0.06 & 0.18 & -0.09 & 0.12 & -0.06 & 0.91 & 0.04 & -0.20 \\
\hline AUTO_2 & -0.05 & 0.03 & 0.20 & -0.02 & 0.06 & 0.02 & 0.91 & 0.02 & -0.08 \\
\hline AUTO_3 & 0.08 & -0.10 & -0.01 & 0.15 & -0.02 & 0.10 & 0.88 & 0.03 & -0.05 \\
\hline INNV_1 & 0.03 & 0.04 & 0.17 & 0.09 & -0.04 & -0.01 & 0.08 & 0.87 & 0.00 \\
\hline INNV_2 & 0.06 & -0.04 & 0.01 & 0.16 & 0.03 & -0.06 & 0.04 & 0.86 & 0.00 \\
\hline INNV_3 & -0.05 & -0.07 & 0.28 & 0.11 & 0.26 & -0.09 & 0.04 & 0.78 & 0.04 \\
\hline INNV_4 & 0.06 & -0.12 & 0.11 & 0.13 & 0.19 & -0.17 & -0.05 & 0.75 & -0.05 \\
\hline INQ_1 & -0.12 & -0.03 & 0.03 & -0.03 & -0.03 & -0.04 & -0.01 & -0.02 & 0.95 \\
\hline INQ_2 & -0.02 & 0.02 & 0.03 & -0.01 & 0.00 & 0.01 & 0.03 & -0.02 & 0.93 \\
\hline INQ_3 & -0.09 & 0.04 & 0.04 & 0.01 & 0.00 & -0.10 & 0.00 & -0.05 & 0.93 \\
\hline
\end{tabular}


Table 3. Measurement items of the final scales

\begin{tabular}{|c|c|c|c|c|}
\hline \multirow[b]{2}{*}{ Items $^{a}$} & \multicolumn{2}{|c|}{ Factor loadings $(\lambda x)$} & \multicolumn{2}{|c|}{ Error variances $(\boldsymbol{\theta} \delta)$} \\
\hline & $\lambda \mathbf{x}$ & $t$-values & $\theta \delta$ & $t$-values \\
\hline COOP_2 & 0.85 & 11.25 & 0.27 & 5.06 \\
\hline COOP_3 & 0.90 & Fixed & 0.19 & 3.90 \\
\hline COOP_4 & 0.83 & 10.81 & 0.31 & 5.41 \\
\hline COMP_1 & 0.83 & Fixed & 0.31 & 4.79 \\
\hline COMP_2 & 0.91 & 9.75 & 0.18 & 2.89 \\
\hline COMP_5 & 0.75 & 8.34 & 0.43 & 5.85 \\
\hline MARK_2 & 0.88 & Fixed & 0.22 & 5.16 \\
\hline MARK_3 & 0.86 & 12.02 & 0.26 & 5.57 \\
\hline MARK_4 & 0.75 & 9.26 & 0.44 & 6.48 \\
\hline SIZE & 0.84 & Fixed & 0.29 & Fixed \\
\hline AGE & 0.86 & Fixed & 0.26 & Fixed \\
\hline INNV_1 & 0.84 & Fixed & 0.30 & 4.49 \\
\hline INNV_2 & 0.78 & 8.45 & 0.40 & 5.48 \\
\hline INNV_3 & 0.85 & 9.21 & 0.28 & 4.27 \\
\hline PRCT_1 & 1.00 & Fixed & 0.20 & 2.32 \\
\hline PRCT_2 & 0.87 & 5.11 & 0.23 & 3.36 \\
\hline RISK_1 & 0.85 & Fixed & 0.28 & 4.57 \\
\hline RISK_2 & 0.83 & 9.56 & 0.31 & 4.99 \\
\hline RISK_3 & 0.86 & 9.95 & 0.25 & 4.21 \\
\hline AUTO_1 & 0.92 & Fixed & 0.16 & 3.20 \\
\hline AUTO_2 & 0.93 & 13.26 & 0.13 & 2.67 \\
\hline AUTO_3 & 0.74 & 9.41 & 0.45 & 6.43 \\
\hline CAGG_1 & 0.94 & Fixed & 0.11 & 3.53 \\
\hline CAGG_2 & 0.96 & 19.18 & 0.07 & 2.39 \\
\hline CAGG_3 & 0.83 & 12.80 & 0.31 & 6.40 \\
\hline INDS & 0.85 & Fixed & 0.28 & Fixed \\
\hline INTL & 0.84 & Fixed & 0.30 & Fixed \\
\hline INQ_1 & 0.96 & Fixed & 0.08 & 2.44 \\
\hline INQ_2 & 0.88 & 15.06 & 0.22 & 5.58 \\
\hline INQ_3 & 0.90 & 16.13 & 0.18 & 5.02 \\
\hline
\end{tabular}

Table 4. Final multi-item scale reliabilities

\begin{tabular}{|l|c|c|c|c|}
\hline Scales & Alpha $(\boldsymbol{\alpha})$ & Items (n) & CR & AVE \\
\hline Coopetition activities & 0.90 & 3 & 0.90 & 0.74 \\
\hline Competitive intensity & 0.87 & 3 & 0.87 & 0.70 \\
\hline Market performance & 0.86 & 3 & 0.87 & 0.70 \\
\hline Innovativeness & 0.86 & 3 & 0.86 & 0.68 \\
\hline Proactiveness & 0.79 & 2 & 0.81 & 0.68 \\
\hline Risk-taking & 0.88 & 3 & 0.88 & 0.71 \\
\hline Autonomy & 0.90 & 3 & 0.90 & 0.75 \\
\hline Competitive aggressiveness & 0.94 & 3 & 0.94 & 0.84 \\
\hline Informant quality & 0.94 & 3 & 0.94 & 0.84 \\
\hline
\end{tabular}


Table 5. Bivariate correlation coefficients

\begin{tabular}{|c|c|c|c|c|c|c|c|c|c|c|c|c|c|c|}
\hline Latent variables & Mean & SD & 1 & 2 & 3 & 4 & 5 & 6 & 7 & 8 & 9 & 10 & 11 & $\mathbf{1 2}$ \\
\hline 1. Coopetition activities & 4.85 & 0.92 & 1.00 & & & & & & & & & & & \\
\hline 2. Competitive intensity & 4.30 & 1.18 & $-0.25 * * *$ & 1.00 & & & & & & & & & & \\
\hline 3. Market performance & 4.55 & 0.93 & -0.02 & $-0.15^{*}$ & 1.00 & & & & & & & & & \\
\hline 4. Firm size & 2.53 & 0.72 & -0.05 & -0.08 & 0.04 & 1.00 & & & & & & & & \\
\hline 5. Firm age & 1.51 & 0.34 & $0.64^{* * * *}$ & $-0.21 * * *$ & -0.02 & $-0.17 * *$ & 1.00 & & & & & & & \\
\hline 6. Industry experience & 4.40 & 1.09 & -0.05 & -0.01 & $0.85^{* * *}$ & 0.12 & -0.06 & 1.00 & & & & & & \\
\hline 7. Innovativeness & 4.43 & 0.87 & 0.09 & -0.10 & $0.30^{* * * *}$ & 0.10 & $0.25^{* * * *}$ & $0.32^{* * * *}$ & 1.00 & & & & & \\
\hline 8. Proactiveness & 4.74 & 0.71 & 0.03 & 0.00 & $0.40^{* * * *}$ & -0.04 & 0.02 & $0.36^{* * * *}$ & 0.34 *** & 1.00 & & & & \\
\hline 9. Risk-taking & 3.34 & 0.93 & -0.03 & 0.03 & 0.04 & 0.09 & -0.08 & $0.15^{*}$ & $0.21^{* * * *}$ & 0.09 & 1.00 & & & \\
\hline 10. Autonomy & 3.84 & 1.14 & 0.01 & -0.03 & $0.26^{* * * *}$ & $-0.18 * *$ & 0.01 & $0.22^{* * * *}$ & 0.11 & 0.08 & 0.04 & 1.00 & & \\
\hline 11. Competitive aggressiveness & 1.98 & 1.00 & $-0.16^{* *}$ & $0.14^{*}$ & 0.06 & \begin{tabular}{c|c|c|}
-0.01 \\
\end{tabular} & $-0.30^{* * * *}$ & 0.11 & -0.13 & 0.04 & $0.21 * * *$ & 0.05 & 1.00 & \\
\hline 12. Degree of internationalisation & 1.96 & 1.94 & -0.03 & $0.23^{* * *}$ & 0.12 & $0.22 * * *$ & -0.11 & 0.17 ** & -0.02 & 0.00 & 0.10 & -0.07 & 0.11 & 1.00 \\
\hline
\end{tabular}

Table 6. Hierarchical regression analysis

\begin{tabular}{|c|c|c|c|c|c|c|c|c|c|c|c|c|}
\hline & \multicolumn{2}{|c|}{ Step 1} & \multicolumn{2}{|c|}{ Step 2} & \multicolumn{2}{|c|}{ Step 3} & \multicolumn{2}{|c|}{ Step 4} & \multicolumn{2}{|c|}{ Step 5} & \multicolumn{2}{|c|}{ Step 6} \\
\hline Independent variables & $\bar{\beta}$ & $t$-values & $\bar{\beta}$ & $t$-values & $\bar{\beta}$ & $t$-values & $\bar{\beta}$ & $t$-values & $\bar{\beta}$ & $t$-values & $\bar{\beta}$ & $t$-values \\
\hline Firm size & -0.05 & -0.70 & -0.05 & -0.72 & -0.06 & -0.86 & -0.09 & -1.22 & -0.08 & -1.21 & -0.08 & -1.11 \\
\hline Firm age & -0.02 & -0.11 & -0.05 & -0.26 & -0.13 & -0.65 & $\begin{array}{c}-0.14 \\
\end{array}$ & -0.73 & -0.13 & -0.65 & -0.22 & -1.10 \\
\hline Industry experience & 0.69 & \begin{tabular}{|l}
$13.47 * * * *$ \\
\end{tabular} & 0.69 & $13.40 * * *$ & 0.66 & $13.08^{* * * *}$ & 0.66 & $13.42 * * *$ & 0.66 & $13.29 * * *$ & 0.66 & $13.34 * * * *$ \\
\hline Innovativeness & 0.02 & 0.34 & 0.03 & 0.37 & 0.02 & 0.25 & 0.01 & 0.22 & 0.02 & 0.26 & 0.02 & 0.39 \\
\hline Proactiveness & 0.14 & $1.78^{*}$ & 0.13 & $1.74 *$ & 0.11 & 1.44 & 0.12 & 1.62 & 0.12 & 1.63 & 0.10 & 1.37 \\
\hline Risk-taking & -0.10 & $-1.75^{*}$ & -0.10 & $-1.75^{*}$ & -0.11 & $-2.08 * *$ & $\begin{array}{c}-0.11 \\
\end{array}$ & $-2.08 * *$ & -0.11 & -2.09 ** & -0.11 & $-2.03^{* *}$ \\
\hline Autonomy & 0.05 & 1.15 & 0.05 & 1.13 & 0.05 & 1.12 & 0.05 & 1.09 & 0.05 & 1.07 & 0.04 & 0.99 \\
\hline Competitive aggressiveness & -0.02 & -0.33 & -0.02 & -0.34 & -0.06 & -1.20 & -0.05 & -0.96 & -0.05 & -0.92 & -0.05 & -0.96 \\
\hline Degree of internationalisation & 0.00 & 0.09 & 0.00 & 0.08 & 0.03 & 1.03 & 0.04 & 1.51 & 0.04 & 1.50 & 0.03 & 1.02 \\
\hline Coopetition activities & & & 0.02 & 0.28 & 0.03 & 0.45 & 0.00 & 0.02 & 0.02 & 0.20 & -0.02 & -0.20 \\
\hline Coopetition activities squared & & & & & -0.07 & $-2.88 * * *$ & -0.06 & $-2.50^{* * * *}$ & -0.06 & $-2.34 * *$ & -0.05 & $-1.94 *$ \\
\hline Competitive intensity & & & & & & & -0.11 & $-2.51 * * *$ & -0.04 & -0.19 & -0.09 & -0.38 \\
\hline Coopetition activities $\mathrm{x}$ competitive intensity & & & & & & & & & -0.01 & -0.28 & 0.00 & 0.00 \\
\hline Coopetition activities squared $\mathrm{x}$ competitive intensity & & & & & & & & & & & -0.10 & $-1.82 *$ \\
\hline & & & & & & & & & & & & \\
\hline Model fit summary & & & & & & & & & & & & \\
\hline $\mathrm{R}^{2}$ & 0.75 & & 0.75 & & 0.78 & & 0.79 & & 0.79 & & 0.80 & \\
\hline Adjusted $\mathrm{R}^{2}$ & 0.73 & & 0.73 & & 0.75 & & 0.76 & & 0.76 & & 0.77 & \\
\hline Change statistics & & & & & & & & & & & & \\
\hline$\Delta \mathrm{R}^{2}$ & 0.75 & & 0.00 & & 0.03 & & 0.01 & & 0.00 & & 0.01 & \\
\hline$\Delta F$-statistic & $30.93 * * *$ & & 0.08 & & $8.28 * * * *$ & & $6.30^{* * *}$ & & 0.08 & & $3.29 *$ & \\
\hline
\end{tabular}




\section{Appendix 1. Interview guide used in the qualitative stage}

The questions listed below took place in a semi-structured format. This allowed the research team to follow a guide - with some flexibility to explore pertinent issues as they arose (see Diamantopoulos and Cadogan, 1996).

\section{About the interviewee}

1. What is your current role in the business and what does it involve?

2. How many years have you held this position in the organisation?

3. How many years have you worked in the wine industry (New Zealand and globally)?

Guided by Nemkova et al. (2012); Crick (2018); Felzensztein et al. (2019).

\section{Reasons for engaging in coopetition strategies}

1. What are the main reasons that you collaborate with your competitors?

2. In what ways do you cooperate with your rivals (like information-sharing)?

3. Have you collaborated with your competitors for a long time?

Guided by Bengtsson and Kock (1999); Rusko (2011); Bouncken and Kraus (2013); Hoffmann et al. (2018).

\section{Types of coopetition strategies}

1. Do you collaborate with your competitors in formal and/or informal ways (with examples)?

2. Do you have contractual agreements with the competitors that you collaborate with (with examples)?

3. To what extent do you only cooperate with your competitors in this region (or throughout the country)?

Guided by Bengtsson and Kock (2000); Chetty and Wilson (2003); Lavie (2006); Bouncken and Fredrich (2016); Arslan (2018).

\section{Non-linear (inverted U-shaped) relationship between coopetition activities and market performance}

1. Do you think that there is such a thing as an "optimal-level" of collaborating with your competitors (with examples)?

2. What would happen if you cooperated with rival firms to a minimal extent (with examples)?

3. What consequences would occur if you collaborated with your competitors to an excessive degree (with examples)?

4. Can you talk about any instances of the problems associated with working with rival firms (with examples)?

Guided by Luo et al. (2007); Ang (2008); Ritala and Hurmelinna-Laukkanen (2013); Crick (2019).

\section{Moderating role of competitive intensity affecting the non-linear (inverted U-shaped) relationship between} coopetition activities and market performance

1. Do you consider the rivalry within this industry to be a factor that helps or hinders your success when collaborating with competitors?

2. Can you talk about how domestic versus international competitiveness affects your performance?

3. Are you, as a business, more cooperative or competitive domestically or internationally (with examples)?

Guided by Ritala (2012); Park et al. (2014); Bengtsson et al. (2016); Gnyawali et al., 2016; Shu et al. (2017); Cui et al. (2018).

\section{Closing questions about the business}

1. How many part-time and full-time employees does the business have?

2. What year was the company founded?

3. What percentage of the firm's sales originates from export markets?

4. Which countries does the business export to and why?

Guided by Diamantopoulos and Cadogan (1996); Cadogan et al. (2009); Nemkova et al. (2012). 


\section{Appendix 2. Full-list of the multi-item measurement scales}

\section{Coopetition activities}

In our organisation...

- COOP_1 - ... we cooperate with our competitors extensively

- COOP_2 - ... we share assets (e.g., equipment) with our competitors

- COOP_3 - ... we cooperate with our rivals to achieve a common goal

- COOP_4 - ... an active collaboration with rival firms is important to us

Anchors: 1 = very strongly disagree to 7 = very strongly agree (adapted from Bouncken and Kraus, 2013; Bouncken et al., 2018).

\section{Competitive intensity}

In our industry...

- COMP_1 - ... competition is cut-throat

- COMP_2 - ... there are many "promotion wars"

- COMP_3 - ... anything that one competitor can offer, others can match readily

- COMP_4 - ... price competition is common

- COMP_5 - ... one hears of a competitive move almost every day

Anchors: 1 = very strongly disagree to 7 = very strongly agree (adapted from Jaworski and Kohli, 1993; Grewal and Tansuhaj, 2001).

\section{Market performance}

Please evaluate the performance of your business over the past year (twelve months) relative to your major competitors:

- MARK_1 - Market share growth

- MARK_2 - Growth in sales revenue

- MARK_3 - Acquiring new customers

- MARK_4 - Increasing sales from existing customers

Anchors: $1=$ much worse than competitors to $7=$ much better than competitors (adapted from Vorhies and Morgan, 2005; Vorhies et al., 2009).

\section{Proactiveness}

In our organisation...

- $\quad$ PRCT_1 - ... we exploit anticipated changes in our markets ahead of our rivals

- PRCT_2 - ... we seize initiatives whenever possible in our operations

- PRCT_3 - ... we act opportunistically to shape our business environment

Anchors: 1 = very strongly disagree to 7 = very strongly agree (adapted from Sundqvist et al., 2012; Boso et al., 2013).

\section{Risk-taking}

In our organisation...

- $\quad$ RISK_1 - ... top managers, in general, tend to invest in high-risk strategies

- RISK_2 - ... top managers show a great deal of tolerance for high-risk strategies

- RISK_3 - ... our strategies are characterised by a strong tendency to take risks

Anchors: 1 = very strongly disagree to 7 = very strongly agree (adapted from Sundqvist et al., 2012; Boso et al., 2013).

\section{Autonomy}

In our organisation...

- AUTO_1 - ... employees behave autonomously in our operations 
- AUTO_2 - ... employees act independently complete tasks

- AUTO_3 - ... employees are self-directed in pursuit of market opportunities

Anchors: 1 = very strongly disagree to 7 = very strongly agree (adapted from Sundqvist et al., 2012; Boso et al., 2013).

\section{Innovativeness}

In our organisation...

- INNV_1 - ... we are known as an innovator

- INNV_2 -... we promote new, innovative products/services

- INNV_3 - ... we provide leadership in developing new products/services

- INNV_4 - ... we constantly experiment with new products/services

Anchors: $1=$ very strongly disagree to 7 = very strongly agree (adapted from Sundqvist et al., 2012; Boso et al., 2013).

\section{Competitive aggressiveness}

In our organisation...

- CAGG_1 - ... we typically adopt a "kill the competition" posture in our markets

- CAGG_2 - ... we take hostile steps to achieve competitive goals in our markets

- CAGG_3 - ... our actions toward competitors can be termed as aggressive

Anchors: 1 = very strongly disagree to 7 = very strongly agree (adapted from Sundqvist et al., 2012; Boso et al., 2013).

\section{Informant quality}

To what extent do the statements below describe your agreement/disagreement for completing this survey?

- INQ_1 - I am confident that my answers reflect my organisation's situation

- INQ_2 - This survey deals with issues I am very knowledgeable about

- INQ_3 - My role qualifies me as an appropriate person to complete this survey

Anchors: 1 = very strongly disagree to 7 = very strongly agree (adapted from Katsikeas et al., 2006; Hultman et al., 2009). 
Appendix 3. Characteristics of the organisations that participated in the qualitative stage

\begin{tabular}{|c|c|c|c|c|c|c|}
\hline Firm & $\begin{array}{c}\text { Average price } \\
(\$ N Z)^{\mathrm{a}}\end{array}$ & $\begin{array}{c}\text { Year } \\
\text { founded }\end{array}$ & $\begin{array}{c}\text { Full-time } \\
\text { employees }\end{array}$ & $\begin{array}{l}\text { Part-time } \\
\text { employees }\end{array}$ & Export ratio $^{b}$ & Key export market(s) \\
\hline 1 & 28.56 & 1986 & 12 & 21 & $30 \%$ & China, Hong Kong, and Japan \\
\hline 2 & 17.88 & 1990 & 30 & 17 & $40 \%$ & United States and China \\
\hline 3 & 16.32 & 1999 & 60 & 33 & $30 \%$ & Australia and United States \\
\hline 4 & 18.94 & 1980 & 12 & 3 & $50 \%$ & China, Belgium, and Australia \\
\hline 5 & 14.72 & 1987 & 60 & 31 & $5 \%$ & Not applicable \\
\hline 6 & 26.65 & 1986 & 17 & 2 & $80 \%$ & United Kingdom and Canada \\
\hline 7 & 11.59 & 1992 & 10 & 1 & $5 \%$ & Not applicable \\
\hline 8 & 24.26 & 1989 & 24 & 7 & $65 \%$ & United Kingdom \\
\hline 9 & 17.30 & 1998 & 30 & 12 & $95 \%$ & Japan and Germany \\
\hline 10 & 37.82 & 1988 & 10 & 6 & $0.5 \%$ & Not applicable \\
\hline 11 & 21.84 & 2002 & 50 & 27 & $80 \%$ & United Kingdom and Canada \\
\hline 12 & 16.99 & 1932 & 35 & 19 & $30 \%$ & Japan and United States \\
\hline 13 & 22.34 & 1988 & 12 & 3 & $10 \%$ & Australia \\
\hline 14 & 28.11 & 1999 & 18 & 2 & $50 \%$ & Canada and United States \\
\hline 15 & 16.99 & 1990 & 25 & 22 & $95 \%$ & United Kingdom \\
\hline 16 & 31.76 & 2000 & 15 & 4 & $30 \%$ & China and Hong Kong \\
\hline 17 & 34.55 & 2001 & 10 & 6 & $20 \%$ & United States and Australia \\
\hline 18 & 21.73 & 1998 & 15 & 8 & $50 \%$ & Germany \\
\hline 19 & 18.32 & 1989 & 60 & 34 & $40 \%$ & China, Japan, and Hong Kong \\
\hline 20 & 25.73 & 2003 & 29 & 13 & $0.5 \%$ & Not applicable \\
\hline
\end{tabular}

